Este obra forma parte del acervo de la Biblioteca Jurídica Virtual del Instituto de Investigaciones Jurídicas de la UNAM www.juridicas.unam.mx

\title{
ELECCIONES, SISTEMA DE PARTIDOS, DEMOCRACIA \\ Y CIUDADANÍA EN HONDURAS (1980-2013)
}

\author{
Salvador ROMERO BALLIVIÁN ${ }^{1}$
}

\section{Sumario:}
I. Introducción
II. Logros y límites de la democratización
III. Ciudadanía, partidos y elecciones
IV. Conclusión: la elección de 2013 ¿la transición histórica del sistema de partidos y la reconfiguración de las elecciones?

\section{INTRODUCCIÓN}

Como en el resto de América Latina, las elecciones en Honduras siguieron un azaroso curso. ${ }^{2}$ Fueron fundamentales para una República que sólo concebía la legitimidad otorgada por la ciudadanía, y secundarias porque hasta mediados del siglo XX, quizá apenas tres, se adecuaron a parámetros mínimos de respeto de la voluntad de los

\footnotetext{
${ }^{1}$ Doctor en sociología política en el Instituto de Estudios Políticos de París.

${ }^{2}$ Esta investigación es tributaria de fuentes bibliográficas, como se estila en un trabajo académico. Sin embargo, se enriqueció de manera sustancial gracias a las labores que tuve como director del Instituto Nacional Demócrata (NDI) en Honduras, que entre 2011-2014 me permitieron dar decenas de talleres a todos los partidos en varias ciudades, participar en conversatorios y seminarios multipartidarios, tener encuentros informales con actores clave de la política, las instituciones, la sociedad civil y la comunidad internacional, colaborar con la observación electoral de Hagamos Democracia. Una versión más extensa, abarcando el periodo desde 1948, texto que fue publicado por primera vez en el libro Democracia, elecciones y ciudadanía en Honduras, Tegucigalpa, Instituto Nacional Demócrata, 2014. Los comentarios, sugerencias y críticas recibidos han enriquecido, y confiemos que también mejorado esta versión.
} 
Este obra forma parte del acervo de la Biblioteca Jurídica Virtual del Instituto de Investigaciones Jurídicas de la UNAM

electores. ${ }^{3}$ Ellas se celebraron en los intervalos que dejaron los golpes de Estado, los enfrentamientos fratricidas de las facciones políticas y cuando se organizaron, distaron de ser siempre sinónimo de voluntad popular aceptada o de competencia mínimamente libre.

Más allá de las caricaturas y las frases lapidarias sobre la "República bananera" o las "elecciones estilo Honduras" que aún forman parte de las referencias corrientes de la vida política, ${ }^{4}$ la historia electoral y partidaria de Honduras es interesante y revela profundas dinámicas sociopolíticas. En efecto, muestra la evolución política y social de una sociedad, a la vez típica de la región y singular, por ser la única que a principios del siglo XXI continuaba estructurada por un bipartidismo de raíz decimonónica; pone en evidencia los procesos de modernización política e institucional así como los límites de esos cambios; ilustra la tensión entre las influencias y presiones externas, y los movimientos endógenos; $y$, como a menudo con las elecciones, termina diciendo mucho sobre los modos de funcionamiento de la política, de la estructura social y de las pautas culturales. $^{5}$

El texto pretende esbozar las líneas gruesas de dichos juegos desde el retorno a la democracia, para percibir mejor las permanencias y las transformaciones de las elecciones, proponer pistas explicativas y dibujar consecuencias e implicaciones. Antes de un análisis detallado de cada uno de los comicios, destaca las tendencias centrales de cada periodo y ofrece hipótesis, algunas puestas a prueba, otras únicamente señaladas para investigaciones ulteriores.

Constituye el punto de partida la fase iniciada en 1980, marca el regreso a la democracia y abre una inédita experiencia de procesos electorales periódicos y

\footnotetext{
${ }^{3}$ Según Petra Bendel, las únicas que calificarían como "relativamente correctas" serían las de 1924, 1928 y 1932. Bendel, Petra, “Honduras" en Dieter, Nohlen (coord.), Enciclopedia electoral latinoamericana y del Caribe, San José, Instituto Interamericano de Derechos Humanos, 1993, p. 393.

${ }^{4}$ Cfr. Las declaraciones de Mauricio Villeda a propósito de las internas de 2012: “una veeduría de las elecciones... para evitar que vuelvan a haber elecciones estilo Honduras en "el principal problema de este gobierno es el desorden", El Heraldo, 17 de septiembre de 2012.

${ }^{5}$ Para aproximaciones teóricas a este enfoque, cfr. Garrigou, Alain, Histoire sociale du suffrage universel en France (1848-2000), París, Seuil, 2002; Deloye, Yves y Ihl, Olivier, L'acte du vote, París, Presses de Sciences Po., 2008.
} 
Este obra forma parte del acervo de la Biblioteca Jurídica Virtual del Instituto de Investigaciones Jurídicas de la UNAM

competitivos, aunque rara vez exentos de reproches y sospechas. A continuación, aborda los dilemas que plantea el retroceso de la participación y analiza las relaciones entre ciudadanía y partidos. Por último, explora facetas de la transición histórica del sistema de partidos y de elecciones, comenzada con la crisis política de 2009 y prolongada en la presidencial de 2013.

\section{LOGROS Y LÍMITES DE LA DEMOCRATIZACIÓN}

\section{El retorno a la democracia y las características}

políticas de las elecciones

Como la mayoría de los países latinoamericanos, Honduras se integró en la tercera ola de la democracia ${ }^{6}$ a finales de los años setenta e inicios de los ochenta y la inauguró en América Central. Su ruta resultó singular en un área convulsionada por la violencia. En efecto, no conoció ni guerrillas que ganaron el poder o al menos hicieron tablas con el Estado (Nicaragua, El Salvador) ni la represión en una escala devastadora (Guatemala). Se produjo, entonces, una transición más clásica de un ejército que suprimió las libertades políticas y practicó un "pluralismo limitado", 7 mostrándose tolerante con empresarios, Iglesias, fracciones conservadoras de los partidos y organizó el escenario para el traspaso del poder a los civiles. La limitada violencia política debe subrayarse por su carácter atípico en la región. Contribuyó la apertura militar a demandas sociales que logró incluso un soporte sindical y de movimientos sociales así como la convivencia del Ejército con los partidos mayoritarios, en especial el Partido Nacional (PN), que atenuó la persecución partidaria.

El guión del retorno a la democracia tuvo dos etapas: la Asamblea Constituyente de 1980 y la presidencial de 1981. La primera se inscribió en una tradición nacional pues se trató de la cuarta en la segunda mitad del siglo XX. Las Constituyentes sirvieron para legitimar un gobierno de facto -Julio Lozano Díaz en 1956; Oswaldo López Arellano en 1965-, o marcar una fase nueva, de corte más democrático, como la convocada por los militares en 1957. El general Juan Alberto Melgar coqueteó con la idea de utilizarla para reafirmar su poder, lo que provocó su destitución, y al asumir el poder, el general

\footnotetext{
${ }^{6}$ Huntington, Samuel P., "La tercera ola de la democracia" en Diamond, Larry y Plattner, Marc, El resurgimiento global de la democracia, México, UNAM, 1996, pp. 3-23.

${ }^{7}$ Expresión de Juan Linz, La quiebre de las democracias, México, Alianza, 1990.
} 
Este obra forma parte del acervo de la Biblioteca Jurídica Virtual del Instituto de Investigaciones Jurídicas de la UNAM

Policarpo Paz (1978-1980) la Asamblea Constituyente de 1980 terminó en la segunda categoría. Ese propósito, junto con el interés norteamericano por los derechos humanos y la democracia, auspiciado por el gobierno de jimmy Carter le aseguró varias condiciones competitivas.

Los militares liberalizaron el ambiente político con cautela y encuadraron el proceso, cerraron el paso al Partido Demócrata Cristiano (PDC) y a los marxistas, que juntos terminaron convocando a la abstención; aceptaron una campaña plural reservada sólo a los tradicionales PN y Partido Liberal (PL) y al Partido de Innovación y Unidad (PINU), creado por intelectuales y profesionales urbanos después de la breve guerra con El Salvador (1969). Los resultados de las urnas fueron respetados, bajo este marco tutelado, Honduras inició la ruta hacia la democracia.

En un desenlace que recuerda lo acontecido en la Constituyente 1957, los liberales triunfaron, se colocaron como la alternativa democrática luego de un periodo autoritario asociado con el nacionalismo. En el medio siglo precedente, los roles políticos parecieron distribuirse entre un nacionalismo gobernante, regímenes militares relativamente próximos a esa corriente, y un liberalismo con cortos intervalos de gobierno, que aprovechó los tiempos de oposición para acumular fuerzas y emerger victorioso en las aperturas democráticas.

El liberalismo carecía de mayoría absoluta y de propuestas de cambios fuertes, ya que su ala progresista perdió fuerza. A meses del triunfo de la guerrilla sandinista y del pico de la guerra civil salvadoreña, el liberalismo se desvinculó de cualquier propuesta nítida de izquierda. En realidad, ninguno de los dos partidos llegó con un texto base elaborado y la Constitución fue un trabajo bipartidista, ${ }^{8}$ inevitable, pues el PL y el PN empataron en el número de constituyentes y el escaño restante lo ocupó el PINU. La Constituyente adoptó un perfil político modesto y conciliador; se apresuró a ratificar al general Paz como presidente de la República, que a su vez distribuyó portafolios en el gabinete con un criterio multipartidista, incluyendo a líderes nacionalistas y liberales. La Constitución reconoció las prerrogativas de los militares que aún controlaban el Ejecutivo y gozaban de la simpatía nacionalista. Los civiles necesitaron hacer más concesiones a las fuerzas

\footnotetext{
${ }^{8}$ Ramos, Oswaldo “Evolución del Estado de derecho en Honduras en las últimas tres décadas" en Carbonell, Miguel, Carpizo, Jorge et al. (coords.), Tendencias del constitucionalismo en Iberoamérica, México, UNAMIDEA, 2009, p. 391.
} 
Este obra forma parte del acervo de la Biblioteca Jurídica Virtual del Instituto de Investigaciones Jurídicas de la UNAM

armadas - que varios de sus pares del sur del continente, sucedieron a militares acorralados, aislados, desacreditados y sin función estratégica en la Guerra Fría-. En ese sentido, la transición a la democracia reflejó un consenso de elites civiles y militares que disipó temores y previno tensiones políticas. En América Central, incluso cuando devolvieron la presidencia, los militares mantuvieron una influencia relevante durante los años ochenta, facilitada por la perduración de las guerras civiles. Ello se aplicó también a Honduras, base de retaguardia para la "contra" nicaragüense, y donde ejecutaron una represión de baja intensidad contra la izquierda. ${ }^{9}$ Recién en la última década del siglo XX se acotaron los espacios de decisión reservados a los militares, entre los acuerdos de paz, el achicamiento liberal del Estado y el impulso de corrientes institucionalistas.

La Constitución de 1980 ha resultado la más longeva, se enmarcó en los principios de los textos previos y en los preceptos acostumbrados del constitucionalismo latinoamericano; aportó pocas innovaciones, aunque extendió y preservó mejor los derechos ciudadanos; conservó el sistema presidencialista, con un presidente elegido por cuatro años en comicios de una sola vuelta, acompañado de la elección proporcional de los congresistas fijada por la Constitución de 1957. En la línea de los países latinoamericanos que volvían a la democracia, prohibió la reelección presidencial, con un carácter absoluto, señal de la viveza del recuerdo de la dictadura de Tiburcio Carías. Incluso, ese artículo, junto con la forma de gobierno, el territorio o el periodo presidencial hace parte de las disposiciones "pétreas" de la Constitución pues no existe posibilidad, dentro de la misma Constitución, de reformarlos o suprimirlos (artículo 347 de la Constitución). Empero, el bemol entre la norma y la práctica se sintió pronto: el primer presidente del flamante periodo democrático, el liberal Roberto Suazo Córdova acarició el proyecto de extender su permanencia en el poder; abrió la primera crisis de consideración de la democracia; forzó una mediación militar, que a pesar de ser discreta demostró que el poder civil no pudo resolver por sí mismo el conflicto y requirió un árbitro externo; confirmó el predominio de las visiones instrumentales de la democracia y obligó a una inconstitucional y alambicada salida jurídica en la presidencial de 1985, conocida popularmente como "opción B", una especie de ley de lemas uruguaya que permitió múltiples candidaturas presidenciales por partido en la elección y de la cual

${ }^{9}$ Cfr. Becerra, Longino, Cuando las tarántulas atacan, Tegucigalpa, Batkun, 1987. 
Este obra forma parte del acervo de la Biblioteca Jurídica Virtual del Instituto de Investigaciones Jurídicas de la UNAM

emergió un gobierno frágil. ${ }^{10}$

La segunda etapa fue la presidencial de 1981. Con el empuje del triunfo en la Constituyente, el PL llevó a Suazo a la Presidencia, ya que resultó ganador con 53.9\%. Elección que tuvo al menos tres características que marcaron la pauta de los comicios siguientes; inauguró una fase sin precedentes: la sucesión de escrutinios periódicos, pluralistas, correctos en su desarrollo, en los cuales la voluntad popular fue el criterio para designar la titularidad del poder; se desarrolló de manera bipartidista, reservando la disputa presidencial al PN y PL, relegando a las otras fuerzas a un papel secundario. Por último, estableció el papel preponderante del liberalismo en el sistema político en las dos últimas décadas del siglo XX. Por tanto, cada uno de estos tres aspectos merece un análisis.

En una perspectiva histórica, la fase democrática que nace en 1982 constituye una inflexión. Ningún militar se apropió del gobierno mediante un golpe de Estado; desaparecieron los fraudes burdos del oficialismo para conservar el poder; la alternancia con la oposición se inscribió en el horizonte habitual, produciéndose cinco traspasos a la Presidencia de un partido a otro desde la gestión de Suazo. En síntesis, la elección cuatrienal se convirtió en el momento privilegiado de la política.

En consideración de la turbia historia electoral, la puntual organización de elecciones fundadas en el respeto de la voluntad ciudadana constituye un progreso significativo. Algunas de las causas de la evolución excedieron el marco local para ligarse con profundas evoluciones internacionales. Honduras se inscribió en una de las tendencias relevantes de América Latina, donde los criterios básicos de elecciones limpias, libres y medio de acceso a cargos públicos mejoraron de manera sostenida, rompiendo con una tradición de elecciones poco o nada competitivas. Entre 1900 y 1980, aproximadamente un tercio de los comicios centroamericanos fueron competitivos, de 1980 a 2000, los cuatro quintos. ${ }^{11}$ El índice de democracia electoral elaborado por el Programa de las Naciones Unidas para el Desarrollo ha progresado en América Latina de 0.28 en 1977 a

\footnotetext{
${ }^{10}$ El Partido Liberal obtuvo la mayoría de los votos pero su candidato más votado y presidente electo, José Azcona, fue superado por el candidato nacionalista más votado. Molina, Guillermo, “Honduras: ¿elección sin ganador", Nueva Sociedad (82), marzo-abril de 1986.

${ }^{11}$ Lehoucq, Fabrice, “Elections, droit de suffrage et participation électorale en Amérique Centrale 1900-2000", Problèmes d'Amérique Latine (54), otoño de 2004, p. 18.
} 
Este obra forma parte del acervo de la Biblioteca Jurídica Virtual del Instituto de Investigaciones Jurídicas de la UNAM

0.86 en 1990 y 0.96 en 2008, siendo 1 la máxima calificación. ${ }^{12}$

Los actores políticos facilitaron esta transición, ensanchando el campo para una participación de las distintas fuerzas políticas y sociales. A diferencia del proceso tutelado de la Constituyente de 1980, la presidencial de 1981 tuvo un carácter más plural pues el PDC obtuvo la personalidad jurídica e ingresó en la carrera; en 1994 fue Unificación Democrática (UD), fusión de varias organizaciones, el primer partido que compitió reivindicando una etiqueta de izquierda, gracias a la extensión de las fronteras democráticas que trajo los acuerdos de paz centroamericanos. En 2013, la elección se celebró con el inédito número de nueve partidos.

Los avances no eximieron que se presentaran crisis de consideración, como la de 1985 y sobre todo la de 2009. La primera la desató el ánimo prorroguista de Suazo. En la segunda, luego de una álgida disputa en torno a la iniciativa del presidente Manuel Zelaya de organizar, al margen del Tribunal Supremo Electoral (TSE), un referéndum para la convocatoria a una Asamblea Constituyente se defenestró al presidente con la participación del Ejército, el Congreso, la Corte Suprema de Justicia (CSJ) y otras instituciones. El conflicto reveló disfunciones graves de la sociedad, las instituciones y la clase política, ${ }^{13}$ y colocó al país en la picota internacional. La elección de 2009 se celebró en un ambiente de libertades restringidas y competitividad recortada, ya que los datos de la jornada electoral correspondieron a las preferencias del electorado y generaron una alternancia partidaria en el poder. ${ }^{14}$ El denominador común fue la pretensión, real o supuesta, del presidente de encontrar un mecanismo para permanecer en el poder y en ambas ocasiones, la resistencia provino de la oposición y de fracciones relevantes de la misma organización del mandatario. Amén de esas crisis, han sido recurrentes los conflictos entre los poderes, y el Judicial lleva la peor parte: magistrados de la CSJ fueron removidos, a menudo con procedimientos de endeble legalidad y larvados conflictos políticos, en los gobiernos de Suazo, Callejas y Lobo.

La segunda característica de la elección de 1981 y de las que la siguieron hasta 2009, fue el bipartidismo, arraigado en la historia pero ya excepcional en el contexto

\footnotetext{
${ }^{12}$ Programa de las Naciones para el Desarrollo, Organización de los Estados Americanos, Nuestra democracia, México, PNUD-OEA, 2011, p. 65.

${ }^{13}$ Para que los hechos no se repitan, San José, Comisión de la Verdad y la Reconciliación, 2011. p. 391.

${ }^{14}$ Taylor-Robinson, Michelle, “The Honduran General Election of 2009”, Electoral Studies (30), 2011, p. 370.
} 
Este obra forma parte del acervo de la Biblioteca Jurídica Virtual del Instituto de Investigaciones Jurídicas de la UNAM

latinoamericano. Si al despuntar el siglo XXI, menos del 15\% de los partidos relevantes en América Latina fueron fundados antes de 1925, Honduras inscribía sus dos partidos principales en esa fase y carecía de organizaciones significativas, creadas luego (un rasgo compartido sólo con Colombia y Paraguay). ${ }^{15}$ En la elección de la apertura, los candidatos liberal y nacionalista acapararon $95.5 \%$ del voto, quedando apenas $2.5 \%$ para el candidato del PINU, y $1.6 \%$ para el del PDC.

Como antes, cuando se abrieron ventanas democráticas, los electores confiaron en los partidos históricos. Aunque, desde el retorno a la democracia, la rivalidad se alejó de la polarización, incluso violenta, que caracterizó al país hasta entrado el siglo XX. Se instaló un bipartidismo moderado, de escasa volatilidad, poco ideológico, centrípeto y de anclaje conservador. En las legislaturas de 1994, 1997, 2001 y 2005, en un autoposicionamiento ideológico entre -0 , izquierda y 10 , derecha- el promedio parlamentario fue de 5.4, 6.1, 5.8 y 5.7 respectivamente, con un puntaje de 8.6 para los legisladores del PN y de 5.8 para los del PL. ${ }^{16}$ Esta sensibilidad es compartida con el cuerpo electoral. En 2013, sobre esa misma escala, los simpatizantes del PN, UD, PL y PAC se colocaban entre 7.1 y 5.7; únicamente los de Libre se situaban en el margen izquierdo y aún así, en una postura bastante centrista (4.2). ${ }^{17}$ De hecho, Honduras es una de las naciones latinoamericanas con mayor porcentaje de autoidentificación con la derecha y a la inversa, menor adhesión a la izquierda. En 2013, 39\% de los encuestados se ubicó en la derecha (porcentaje sólo superado en República Dominicana), 12\% en la izquierda (penúltima posición, por delante de Paraguay). ${ }^{18}$

La renovación de la oferta partidaria tampoco tuvo oportunidades para cristalizar el periodo militar que colocó cortapisas a las nuevas organizaciones, a la par que satisfacía algunas ambiciones de cambio social y, en ciertas fases, hasta gozó de la simpatía de las corrientes demócrata-cristiana o comunista. En cierto sentido, el ciclo militar ralentizó cualquier evolución del sistema partidario. Las fuerzas que debutaron en la presidencial

\footnotetext{
${ }^{15}$ Alcántara, Manuel, Partidos políticos latinoamericanos: ¿instituciones o máquinas ideológicas?, México, Gernika, 2006, pp. 90-94.

${ }^{16}$ Universidad de Salamanca, Elites parlamentarias latinoamericanas, Honduras, 1994-2005, p. 17.

${ }^{17}$ Meléndez, Carlos, Honduras, elecciones 2013: compra de votos y democracia, Tegucigalpa, CEDOH-NDI, 2014, p. 13.

${ }^{18}$ Latinobarómetro, Informe 2013, p. 29, www.latinobarometro.org
} 
Este obra forma parte del acervo de la Biblioteca Jurídica Virtual del Instituto de Investigaciones Jurídicas de la UNAM

de 1981, el PINU y el PDC, estaban lejos de contar con estructuras nacionales, liderazgos conocidos o recursos importantes para encarar una campaña electoral. Además, la apuesta del electorado por los partidos o los candidatos con larga trayectoria, previa a los paréntesis militares, fue la tónica en América Latina: se produjo en las primeras elecciones democráticas de Argentina, Bolivia, Chile, Perú y Uruguay.

Por lo tanto, tal vez lo sorprendente fuera menos la hegemonía liberal- nacionalista en el retorno a la democracia sino su permanencia durante tres décadas. El predominio no se desmintió y en los comicios siguientes se acostumbraron a sumar porcentajes vecinos al 95\%. Cifras próximas se encontraron en las alcaldías y en la composición del Parlamento, hasta 2009, cuando por primera vez el bipartidismo contó con menos del $90 \%$ de los diputados. Los votos restantes se los distribuyeron el PINU, el PDC, UD y los escasos candidatos independientes que se animaron a competir para alcaldías o diputaciones.

A los motivos ya señalados para el enraizamiento de los partidos mayoritarios, se requiere añadir las consideraciones sobre las políticas públicas. Aún desde la época militar, aunque su peso en la economía ha sido históricamente limitado, el Estado mostró una sensibilidad mayor a diferencia de otros países de la región (con excepción de Costa Rica), para invertir en áreas sociales, lo que sugiere una cierta receptividad de las elites partidarias frente a las demandas de la población. ${ }^{19}$ Porque Honduras resistió mejor que muchos países latinoamericanos la crisis económica de los años ochenta, el neoliberalismo de los noventa llegó con un paso más discreto, durante la primera administración nacionalista encabezada por Rafael Callejas. Se ahorraron así tanto los efectos más severos de la crisis como de los ajustes estructurales que desmoronaron partidos históricos de América Latina. La mayoría del electorado se desplazó entre azules nacionalistas y rojos liberales con mínima volatilidad, fue más necesaria de subrayarse que el bipartidismo no reposó en mecanismos de mayoría simple, que incentivan sistemas de esa naturaleza sino que se produjo en el esquema proporcional característico de América Latina. ${ }^{20}$ De hecho, hasta en exigentes perspectivas comparadas, el sistema partidario hondureño se caracterizó por su elevada

\footnotetext{
${ }^{19}$ Lehouq, Fabrice "La economía política de la desigualdad en Centroamérica”, Anuario de Estudios Centroamericanos (38), 2012, pp. 98 y 99.

${ }^{20}$ Cfr.Nohlen, Dieter, Sistemas electorales y partidos políticos, México, Fondo de Cultura Económica, 1994.
} 
Este obra forma parte del acervo de la Biblioteca Jurídica Virtual del Instituto de Investigaciones Jurídicas de la UNAM

institucionalización, baja volatilidad electoral, presencia nacional y arraigo territorial. ${ }^{21}$

El tercer rasgo de las elecciones fue el inicial tono colorado del bipartidismo. De los nueve gobiernos entre 1982-2014, cinco fueron liberales y cuatro nacionalistas. EI PN no conservó el gobierno por dos mandatos consecutivos hasta romper la racha con Juan Orlando Hernández en 2013, en tanto que el PL se había acostumbrado a ejercer dos periodos antes de ceder el poder (excepción hecha de 2009, cuando la derrota fue precedida por la defenestración de Zelaya y la ruptura de hecho del Partido Liberal). Luego, el cuadro se equilibró incluso con ventaja nacionalista en el siglo XXI, en contraste con el liberalismo que ofrece una imagen declinante desde la victoria de Carlos Flores en 1997, como si flaquearan las bases de su ventaja (gráfico 1).

El inicial predominio electoral liberal tuvo raíces políticas, sociales y geográficas. En el medio siglo desde la llegada al poder de Carías hasta su retiro militar, los liberales gobernaron un tiempo corto y asociaron la presidencia de Ramón Villeda a una gestión democrática y reformista (1957-1963). El golpe de Estado de 1963 que frustró la probable victoria de Modesto Rodas agrandó la leyenda reformista del partido. Opositores a los militares alimentaron expectativas de libertad, progreso social y honestidad, cubrieron un amplio espectro social y político desde la afinidad con la izquierda a posiciones más bien conservadoras, a las que perteneció el primer candidato, Suazo. Al inicio de la transición democrática, el liberalismo contaba con un panteón extenso de héroes y mártires, ${ }^{22}$ y con una base social menos acostumbrada que la nacionalista a los límites de la administración de la gestión del Estado. En los años primeros de la democracia, el nacionalismo debió aguardar el desgaste de las gestiones liberales y la emergencia de liderazgos carismáticos para revertir su debilidad. Ejemplares de tal dinámica fueron Rafael Callejas y Ricardo Maduro: ambos dominaron las primarias nacionalistas y desarrollaron campañas con el sello de la modernidad, en sintonía con un país más urbano, con nuevos y plurales actores sociales (organizaciones de mujeres, jóvenes, Iglesias, etnias, etcétera.) y con una cultura política un poco más exigente. ${ }^{23}$ Por su parte,

\footnotetext{
${ }^{21}$ Taylor-Robinson, Michelle, "Selección de candidatos al Congreso Nacional de Honduras por los partidos tradicionales" en Freidenberg, Flavia y Alcántara, Manuel, Selección de candidatos, política partidistay rendimiento democrático, México, UNAM-TEDF, Universidad de Salamanca, 2009, pp. 329-333.

${ }^{22}$ Cfr. Roberto Reina, Carlos, Huellas de una lucha, Tegucigalpa, 1997.

${ }^{23}$ Meza, Víctor (coord.), Proceso electoral 2001: monitoreo desde la sociedad civil, Tegucigalpa, CEDOH, FFD,
} 
Este obra forma parte del acervo de la Biblioteca Jurídica Virtual del Instituto de Investigaciones Jurídicas de la UNAM

el liberalismo no logró reemplazar en las nuevas generaciones el recuerdo de Villeda con otra gestión de iguales logros. La nostálgica evocación del reformismo de Villeda medio siglo después subrayaba, por contraste, esa ausencia. ${ }^{24}$ De hecho, volvió a encarnar el reformismo social en contraposición al neoliberalismo económico implantado en la gestión de Callejas pero las sucesivas administraciones de Carlos Reina y Flores aportaron escasas modificaciones a esas líneas. Al final, se distendió el vínculo más espontáneo entre liberalismo, democracia y progreso social.

En el campo social, si bien, ambos partidos cubrieron transversalmente las distintas categorías, el liberalismo llegó a la transición democrática con alianzas con los sectores medios y populares organizados, como sindicatos, gremios de pequeños productores, frentes universitarios, etcétera, que buscaron cobijo en un partido predispuesto a innovaciones sociales; además de que fue opositor a los militares y nacionalistas que mostraban posiciones más cerradas, hasta represivas. Al mismo tiempo, esa mezcla de logros y promesas restó espacio a organizaciones de izquierda. Como en el caso anterior y por razones similares, los lazos con los movimientos sociales se atenuaron y varios sindicatos se desligaron del bipartidismo. Este posicionamiento no menguó las entradas del liberalismo en el mundo empresarial ni cuestionó la economía de mercado. Varios de sus dirigentes connotados vienen directamente de poderosos núcleos empresariales. Por su lado, el nacionalismo, ya desvinculado del periodo militar, remozado en sus cuadros dirigentes incluso sensible a concepciones demócrata cristianas, compite en el terreno social. La entrega de subsidios condicionados, uno de los rostros principales de las políticas sociales latinoamericanas en el inicio del siglo XXI fue un puntal de la administración de Porfirio Lobo. El "Bono 10.000" fue proseguido en la administración de Hernández. ${ }^{25}$

Por último, la geografía de las primeras elecciones lució colorada. Como es habitual,

\section{2, pp. 29-58.}

${ }^{24}$ A modo de ejemplo, esta descripción: “fue la época luminosa, siempre añorada. La del Partido Liberal transformador, la de las grandes conquistas sociales, la que señala la historia patria con el nombre de Ramón Villeda Morales. Cuando la admiración la atraía la nobleza, cuando el liderazgo lo construía el idealismo, cuando el respeto lo ganaba la honestidad". Mejía, Luz Ernestina, "Abanderado", El Heraldo, 8 de septiembre de 2012.

${ }^{25}$ El gobierno de Hernández informó que en los primeros cien días de gestión distribuyó el bono a 251.000 hogares, Presidencia de la República, 100 días trabajando, p.15. 
Este obra forma parte del acervo de la Biblioteca Jurídica Virtual del Instituto de Investigaciones Jurídicas de la UNAM

las pautas de distribución territorial de las preferencias políticas poseen raíces largas y estabilidad relativa en el tiempo. El PL sentó su supremacía en el corazón del país, cubrió la costa norte (departamentos de Colón, Atlántida, Yoro, Cortés, Santa Bárbara) y el centro (Comayagua, Morazán, La Paz, El Paraíso, Olancho). El PN probó su fuerza en la aislada Mosquitia, en el sur (Choluteca y Valle), en la frontera occidental rural (Intibucá, Lempira, Copán). ${ }^{26}$

Esta repartición favorecía al liberalismo, afincado en la zona demográfica urbana, industrial, con movimientos migratorios positivos, mejor desarrollo humano e infraestructura. Al inicio de la transición democrática, el liberalismo apareció como el portavoz de las ciudades, de las categorías que se sentían creadoras de la sociedad moderna, como los obreros, universitarios, intelectuales. El nacionalismo implantado en el occidente rural, pobre, poco alfabetizado, expresaba el sentir de las comunidades más tradicionales. Sin embargo, en una de las evoluciones más significativas -impulsada al inicio por la candidatura de toques modernizadores de Callejas- arrebató progresivamente Tegucigalpa. Así, contrabalanceó el dominio liberal del valle del Sula y generó opciones para disputar la presidencia. De manera simultánea, mientras el liberalismo ha sufrido tasas altas de abstención en sus bastiones, el nacionalismo aprovecha que sus fortalezas coinciden con los departamentos participativos.

La geografía electoral pone en evidencia una dinámica nacional en sus evoluciones. En la primera victoria nacionalista, de la mano de Callejas, en 1989, 16 de 18 departamentos la respaldaron, apenas dos a los liberales. En 1993, éstos recuperaron el gobierno y se impusieron en 13 departamentos; al igual que en 1997. En 2001, los nacionalistas volvieron al mando, con victorias en 16 departamentos. En 2005, Zelaya triunfó en 14 departamentos. En 2009, Lobo venció en todos los departamentos y en la mayoría osciló alrededor de su media nacional, igual que Elvin Santos, el derrotado candidato del PL. La desviación estándar departamental fue de 3.7 para el PN y de 3.3 para el PL, que indican modestas variaciones territoriales. La homogeneización territorial sugiere una nacionalización de la vida política que atenúa las particularidades regionales e implica un

\footnotetext{
${ }^{26}$ Sonnleitner, Willibald, “Las elecciones en México y Centroamérica: polarización o fragmentación”, en Romero Ballivián, Salvador (comp.), Atlas electoral latinoamericano, La Paz, Corte Nacional Electoral, 2007, pp. 209-211.
} 
Este obra forma parte del acervo de la Biblioteca Jurídica Virtual del Instituto de Investigaciones Jurídicas de la UNAM

"debilitamiento y fragmentación territorial del bipartidismo tradicional". ${ }^{27}$ Razones estructurales contribuyen a explicar esa evolución: la extensión de las redes nacionales de medios de comunicación, la mejor integración de las zonas aisladas al juego nacional, el proselitismo partidario fuera de los bastiones y la atenuación de la oposiciones más notorias entre liberales y nacionalistas. Esa tendencia no es irreversible. La ruptura del bipartidismo en 2013 legó una geografía electoral más contrastada.

\section{Las reformas, los progresos y los límites}

\section{de las elecciones en Honduras}

Con la realización periódica de procesos electorales mejoró la calidad de los comicios, se reforzó la transparencia y se ampliaron las oportunidades de decisión de los ciudadanos. El sistema político procuró brindar mayores garantías para el respeto del sufragio a través de continuas reformas constitucionales y legales, políticas y electorales, con el empuje de la sociedad civil y el respaldo de la comunidad internacional. Pese a los avances técnicos, las elecciones continuaron bajo un manto de sospechas, reflejo de la escasa confianza ciudadana en las instituciones y el comportamiento de actores que, a veces, privilegiaron ganancias partidarias sobre el afianzamiento institucional.

Las condiciones para un ejercicio más libre y seguro del sufragio progresaron, en consonancia con las evoluciones en América Latina y muchas veces con un carácter pionero en el triángulo norte centroamericano. Esa precocidad se explicó probablemente por la ausencia de un conflicto armado interno. Las energías pudieron concentrarse en el mejoramiento de las elecciones con un aprovechamiento de las buenas prácticas experimentadas en otros países latinoamericanos o con políticas innovadoras.

En 1985 se adoptó la papeleta única, impresa por el organismo electoral, y distribuida a cada ciudadano en el momento de la votación en lugar de la práctica previa, de impresión y distribución de papeletas a cargo de cada organización. Antes era común que el ciudadano acudiera al centro de votación con su papeleta, lo que facilitaba eventuales presiones sobre los votantes, el clientelismo o la identificación de las preferencias.

Honduras se adelantó a sus vecinos adoptando en 1997 el voto residencial. La

\footnotetext{
${ }^{27}$ Cálix, Álvaro y Sonnleitner, Willibald, "La paradoja hondureña”, en Sonnleitner, Willibald, Explorando los territorios del voto, Guatemala, IHEAL, BID, CEMCA, 2006, p. 27.
} 
Este obra forma parte del acervo de la Biblioteca Jurídica Virtual del Instituto de Investigaciones Jurídicas de la UNAM

descentralización de los recintos de votación mejoró las oportunidades para el ejercicio del sufragio en las comunidades rurales y en los barrios periféricos. La centralización en las cabeceras municipales, frecuente en Guatemala y El Salvador, durante y después de las guerras civiles, buscaba asegurar un mejor control de los partidos y de los mismos organismos electorales, y reducir los riesgos de organizar los comicios en áreas de conflicto. Sin embargo, la decisión perjudicaba a los votantes más pobres y preservaba los lazos clientelistas gracias al traslado, en ciertos lugares directamente con el acarreo de votantes.

Igualmente vanguardista fue la inscripción automática en el censo electoral, una vez que el ciudadano recibía su documento de identidad del Registro Nacional de las Personas (RNP) y la emisión de cédulas con medidas biométricas de seguridad (1987). Se ahorró al ciudadano la realización de una actividad específica para inscribirse en las listas electorales, lo que evitaba perder a las franjas más vulnerables o menos interesadas en los asuntos políticos. Tales avances se desdibujaron con el tiempo. A inicios del ciclo electoral (2012-2013), el RNP indicaba que en sus oficinas tenía aproximadamente un millón de cédulas no reclamadas por los ciudadanos, ${ }^{28}$ cifra gigantesca que se explica por la demora de meses entre el inicio del trámite y la recepción del documento. La entrega se vició de igual forma por la intervención de activistas políticos, convertidos en oportunidades en los intermediarios entre el RNP y los ciudadanos. Los militantes solicitaban los documentos en nombre de los ciudadanos y recibían decenas, cientos de cédulas para distribuirlas entre los ciudadanos afines a la organización. Distribuían las suficientes pero pasadas las elecciones, no se incomodaban en botar las no entregadas, con un pésimo impacto en la imagen del RNP. ${ }^{29} \mathrm{El}$ esquema suponía, además, una administración del RNP compartimentada partidariamente y un cuoteo parecido de los oficiales del Registro Civil. ${ }^{30}$ Por último, ante la débil infraestructura del RNP, la vigencia de las cédulas se prolonga de manera automática por disposiciones legales, lo que restringe la actualización del censo. En 2013, el RNP realizó un significativo esfuerzo para distribuir directamente las cédulas a los ciudadanos a través de brigadas móviles, un paliativo que evitó el manejo sesgado de las tarjetas de

\footnotetext{
28 “Un millón de cédulas sin reclamar en RNP”, El Heraldo, 23 de octubre de 2012.

${ }^{29}$ Registro Nacional de las Personas, Memoria 2013, Tegucigalpa, RNP, 2014, p. 16.

30 “La mayoría de registradores se los dieron a Libre reclaman liberales”, La Tribuna, 8 de mayo de 2013.
} 
Este obra forma parte del acervo de la Biblioteca Jurídica Virtual del Instituto de Investigaciones Jurídicas de la UNAM

identidad y ayudó a apaciguar el ambiente. La renovación completa de la documentación permanece como un desafío estructural, asumido como un compromiso por todos los candidatos presidenciales de 2013 en el "compromiso de garantías mínimas".

La Constitución del retorno a la democracia rompió el control de hecho del Poder Ejecutivo sobre la organización de las elecciones y creó el Tribunal Nacional de Elecciones (TNE), al margen de los tres poderes, adscribiéndose al modelo dominante en América Latina de un organismo autónomo, centralizado, especializado y permanente, iniciado en los años veinte en Uruguay. ${ }^{31}$ El TNE recibió el mandato para los asuntos técnicos y administrativos de la elección así como la función jurisdiccional. Sus responsables eran designados por los partidos (uno por organización) y uno o dos miembros nombrados por la CSJ para asegurar un número impar. El control cruzado debía prevenir las manipulaciones en las fases previas a la jornada electoral y luego la alteración de los resultados. El dominio partidario era completo tanto por la designación de los responsables como y de manera fundamental, por la facultad expedita de remoción. La probabilidad en América Latina de tener elecciones aceptables crece de 0.48 cuando el organismo electoral está dominado por un partido a 0.85 cuando una composición multipartidaria, ${ }^{32}$ modelo adoptado con el TNE.

EI TNE organizó elecciones que permitieron la alternancia pero su labor no despejó las susceptibilidades. Entonces, respondiendo a un amplio compromiso de los partidos en 2001, en 2004 se aprobó una reforma constitucional y una nueva ley electoral. En este proceso, como en otros momentos de acuerdo político (o de crisis), la comunidad internacional generó espacios de diálogo, de acercamiento de actores y de asesoramiento técnico, a menudo considerados de manera favorable. La reforma se saludó como un avance democratizador.

Para reemplazar al TNE, se creó el TSE, con competencias ampliadas y conservando sus características esenciales: un organismo electoral unificado, con responsabilidades técnicas, administrativas y logísticas a la par que jurisdiccionales, aunque sus resoluciones pueden ser impugnadas ante la CSJ en casos de presunta

\footnotetext{
${ }^{31}$ Jaramillo, Juan, “Los órganos electorales supremos" en Nohlen, Dieter et al., Tratado de derecho electoral comparado de América Latina, op. cit., p. 682.

${ }^{32}$ Hartlyn, Jonathan, McCoy, Jennifer et al., "La importancia de la gobernanza electoral y la calidad de las elecciones en América Latina contemporánea", América Latina Hoy, (51), enero de 2008.
} 
Este obra forma parte del acervo de la Biblioteca Jurídica Virtual del Instituto de Investigaciones Jurídicas de la UNAM

inconstitucionalidad. ${ }^{33}$ La modificación sustancial pasó por el retiro a cada partido de la designación de un magistrado y de la facultad de cesarla a simple solicitud; ${ }^{34}$ indicó el deseo de reducir la partidización del organismo para consolidar un árbitro por encima de los jugadores: el TSE debía integrarse con tres magistrados titulares sin ejercicio de responsabilidades partidarias de alto nivel. El paso a una composición apartidista, en principio más independiente y profesional, fue la tendencia latinoamericana al finalizar el siglo XX, con ganancias de legitimidad social y política. ${ }^{35}$ México, Bolivia, Perú o Panamá se encaminaron en esa dirección, señalada previamente por Costa Rica. Finalmente, desprendiéndolo del TSE, la reforma constitucional otorgó autonomía institucional al RNP, responsable del servicio de registro civil y de identificación.

Pese a las reformas, las elecciones despiertan escasa confianza. Según el Latinobarómetro, en 2009, apenas $23 \%$ de los hondureños creía limpias las elecciones, la mitad de la media latinoamericana (44\%). ${ }^{36}$ Corolario previsible, la confianza en el TSE es frágil incluso en los beneficiarios de los cómputos, los parlamentarios. La mucha o bastante confianza en las autoridades electorales fue manifestada por $36.1 \%$ de los congresistas en 2002, y 28.5\% en 2006, el penúltimo guarismo del continente. ${ }^{37}$ En 2011, en una encuesta nacional, $17.3 \%$ expresó su total o mucha confianza en el TSE, en un escenario de escepticismo generalizado con las instituciones. ${ }^{38}$ Las primarias de 2012 fueron juzgadas fraudulentas por $72.7 \%$ contra $20 \%$ que las catalogó como

\footnotetext{
33 Orozco, Jesús, “Evolución y perspectivas de la justicia electoral en América Latina”, Revista Mexicana de Derecho Electoral (1), enero- junio de 2012, p. 121.

${ }^{34}$ Orellana, Edmundo, "Análisis comparativo de la legislación electoral", en CEDOH, Democracia, legislación electoral y sistema político en Honduras, p. 46.

${ }^{35}$ Zovatto, Daniel y Orozco, Jesús, “Reforma política y electoral en América Latina 1978-2007: lectura regional comparada" en Zovatto, Daniel y Orozco, Jesús (coords.), Reforma política y electoral en América Latina 1978 - 2007, México, UNAM-IDEA, 2008, pp. 122 y 123.

${ }^{36}$ Para los datos del Latinobarómetro citados en el texto, cfr. www.latinobarometro.org

${ }^{37}$ Universidad de Salamanca, Boletín datos de opinión: (des) confianza en los organismos y procesos electorales en América Latina, 10-09, julio de 2009, p. 3.

${ }^{38}$ Instituto Nacional Demócrata, Democracia en Honduras: valores y participación política en 2011, Tegucigalpa, NDI, 2011, p. 24.
} 
Este obra forma parte del acervo de la Biblioteca Jurídica Virtual del Instituto de Investigaciones Jurídicas de la UNAM

transparentes. ${ }^{39}$ La elección de 2013 dividió la opinión pública entre quienes creían que los resultados reflejaron la voluntad ciudadana (55.3\%) y quienes pensaban que lo hicieron poco o nada (44.7\%). ${ }^{40}$ Los sectores más instruidos, con mejores ingresos, interesados por la política fueron los más descreídos, como si la desconfianza fuera el signo de la perspicacia, ni la evaluación positiva de la observación internacional afectó esa percepción. Para esos mismos comicios, la Misión de la Unión Europea (UE) concluyó que "los magistrados del TSE lograron actuar, en general, como una institución neutral y, de manera crucial, adoptaron el principio de transparencia como una prioridad". ${ }^{41}$

Cada proceso renueva el temor del retorno del fraude y prepara un terreno fértil para la denuncia, antes, durante o después de la elección. En los altos círculos políticos se admite simultáneamente que si el fraude presidencial es difícil tampoco puede darse por sentada la transparencia, y que la manipulación sería una práctica común en la elección legislativa, facilitada por el sistema complejo de voto preferente con listas abiertas y la composición partidaria de las mesas, que se presta a la compra y venta de credenciales.

Los actores institucionales y políticos hicieron muy poco para fomentar la confianza y en varias oportunidades antepusieron la ventaja partidaria a consideraciones institucionales, incluso legales. Contra la prohibición constitucional de designar como magistrados del TSE a autoridades partidarias, desde 2004, el Parlamento eligió a destacados dirigentes. ${ }^{42}$ En 2005, el presidente del TSE proclamó la victoria de Zelaya prácticamente en ausencia de datos oficialmente tabulados y después integró el primer gabinete de ese presidente. En una célebre declaración, Zelaya indicó que para ganar se debía contar con un margen de $10 \%$ de fraude. En 2009, en la noche de la elección, el TSE proclamó que la participación superó $60 \%$. Al final, las cifras oficiales señalaron una participación menor a 50\%, la más baja desde el retorno a la democracia. Ese año, la tasa de participación era en un dato político sensible por la convocatoria a la abstención de la

\footnotetext{
39 “Hondureños ven fraude en elecciones 24/N", El Heraldo, 23 de enero de 2013.

${ }^{40}$ Borge y asociados, Encuesta nacional de opinión pública postelectoral 2013, pregunta 10 (inédita).

${ }^{41}$ Misión de observación electoral de la Unión Europea, Informe final, Tegucigalpa, Misión de observación electoral de la Unión Europea, 2014, p. 14.

${ }^{42}$ Fernández, Víctor, "Democracia e institucionalidad", $C E D O H$, democracia y gobernabilidad: evaluación y perspectivas, Tegucigalpa, CEDOH, 2010, p. 97.
} 
Este obra forma parte del acervo de la Biblioteca Jurídica Virtual del Instituto de Investigaciones Jurídicas de la UNAM

Resistencia, ${ }^{43}$ que a su vez descalificó la cifra oficial de participación. La propuesta del TSE en 2011 para modernizar la legislación electoral incluyendo "buenas prácticas electorales" latinoamericanas, fue engavetada sin atisbos de discusión parlamentaria.

En un área política de las reformas electorales, a partir de 1989, se incorporaron las elecciones internas para seleccionar autoridades y primarias para elegir candidatos, mediante una evolución progresiva. Comenzó como una práctica del liberalismo "que le permitió insuflarle aires de democratización a sus procesos electorales"; ${ }^{44}$ el nacionalismo se sumó más tarde, porque la elección de 1985 dejó establecido el liderazgo en Callejas. Pasada esa circunstancia excepcional, se convirtió en un ejercicio de los dos grandes partidos que estructuran corrientes o movimientos internos para disputar los cargos presidenciales, parlamentarios y municipales. Los partidos pequeños se acogieron a la posibilidad de designar a sus candidatos mediante convenciones. De una elección primaria acotada al nivel presidencial, los ciudadanos recibieron la posibilidad de escoger también a los candidatos legislativos y municipales. La existencia de papeletas distintas por cada nivel electivo permite el voto cruzado entre corrientes pero no entre partidos (en el momento de votar en la fase primaria, un ciudadano podría elegir al candidato presidencial de la corriente $A$, a su vez el candidato a alcalde de la B y candidatos a diputados de todas las corrientes inscritas). Por último, de un proceso organizado por el partido se pasó a primarias simultáneas, con padrón abierto, organizadas, financiadas y proclamadas por el TSE. Estas evoluciones convierten a las primarias hondureñas en un ejercicio político con escaso parangón internacional. Después de la presidencial, representan el momento más importante de la política, encarada con un despliegue de medios y recursos próximos al utilizado en la contienda general. En 2012 participó casi la mitad de los inscritos en el censo, testimonio de la fortaleza y enraizamiento de los partidos. Honduras presenta una paradoja de talla mundial: como los niveles de participación son próximos en las primarias y en las elecciones generales, tiene un promedio excepcionalmente alto de concurrencia a una selección interna de candidatos y una tasa modesta en elecciones generales.

\footnotetext{
${ }^{43}$ Sonnleitner, Willibald, “Las últimas elecciones en Centroamérica: ¿el quiebre de la tercera ola de las democratizaciones?", pp. 21-25.

${ }^{44}$ Salomón, Leticia, "La nueva ley electoral y su impacto político y cultural", CEDOH, democracia, legislación electoral y sistema político en Honduras, p. 2.
} 
Este obra forma parte del acervo de la Biblioteca Jurídica Virtual del Instituto de Investigaciones Jurídicas de la UNAM

Asimismo, ya en la elección general, los ciudadanos eligen directa y separadamente al presidente, los parlamentarios y los alcaldes. Las papeletas diferenciadas y el voto preferente personalizado en un sistema de listas abiertas para la elección congresal, fueron considerados un adelanto democrático, ya que ofrecieron libertad a los votantes para confeccionar, en la práctica, su propia nómina a partir de las planillas de todos los partidos. ${ }^{45}$ Sin embargo, la simultaneidad de la elección presidencial y parlamentaria así como la identificación partidaria provocan que el voto por congresistas esté altamente condicionado por la preferencia en el nivel presidencial. Aún más, la solidez partidaria mitigó algunos de los habituales efectos corrosivos del voto preferente individualizado sobre la cohesión partidaria, perceptibles en sistemas de partidos menos consolidados. ${ }^{46}$

El férreo control de las cúpulas sobre las candidaturas parlamentarias se atenuó. El perfil de los congresistas se modificó; es cierto, que aún es frecuente que sea el de un hombre de 35 a 54 años con educación superior y capital político familiar, ${ }^{47}$ en un sistema partidario con rasgos dinásticos. No obstante, la presencia femenina se extendió, por lo que los cambios menos perceptibles a primera vista, también modifican la composición parlamentaria. Grupos más populares se abren campo entre las élites tradicionales, profesiones más variadas rompen la monotonía de los abogados, candidatos con menos recorrido político y partidario despuntan para tratar de reconquistar la confianza: "periodistas de todo tipo (de noticias, deportivos, de espectáculos), futbolistas (porteros, defensas, volantes y delanteros), comediantes (nuevos y veteranos), empresarios y comerciantes (contestatarios o no)". ${ }^{48}$ Quizá como antes en otras latitudes, el ejercicio regular del sufragio universal minimice progresivamente el papel de las élites a favor de las clases medias y populares. ${ }^{49}$

\section{La pérdida de capacidad inclusiva de las elecciones}

\footnotetext{
${ }^{45}$ Paz, Ernesto, “La reforma político electoral en Honduras” en Zovatto, Daniel y Orozco, Jesús (coords.), Reforma política y electoral en América Latina 1978-2007, pp. 641 y 642.

${ }^{46}$ Cfr. Tuesta, Fernando, "Un voto letal: el voto preferente y los partidos políticos en el Perú", Revista de Derecho Electoral (15), enero-julio de 2013, pp. 251-270.

47 Programa de las Naciones para el Desarrollo, Informe sobre desarrollo humano-Honduras 2011, Tegucigalpa, PNUD, 2012, p. 132.

${ }^{48}$ Cálix, Miguel, “¿En quién confiar”, El Heraldo, 22 de julio de 2012.

${ }^{49}$ Cfr. Garrigou, Alain, op. cit., pp. 283-297.
} 
Este obra forma parte del acervo de la Biblioteca Jurídica Virtual del Instituto de Investigaciones Jurídicas de la UNAM

\section{y el descenso de la participación}

El principal desafío para el sistema político y electoral es encarar el debilitamiento de su capacidad para generar participación, lograr que la inclusión en los listados se traduzca en asistencia a las urnas. La talla del censo electoral casi se triplicó entre 1985-2013 (181.5\%), estableció la mejor marca centroamericana y probó la efectividad de la inscripción automática. Más del $91 \%$ de los hondureños figuran en el censo, sin distinciones significativas entre áreas urbanas y rurales, hombres y mujeres. ${ }^{50}$

Sin embargo, esa dimensión del censo no se refleja en las urnas. De 1985 a 2014, la cantidad de votantes sólo se duplicó (aumentó en 104\%), en tanto que Guatemala la triplicó en un lapso parecido. La participación hondureña en elecciones presidenciales del siglo XXI es la más baja de América Central, con 57.4\%. El país más cercano es El Salvador (61.4\%) y Panamá encabeza la lista (76\%). Posición que es más preocupante que el promedio centroamericano, ya que es menor que el sudamericano. La presidencial de 2009 marcó el peor punto, con una participación inferior a 50\%. Cierto, ella se organizó en una coyuntura atípica, a pocos meses de la defenestración del presidente Zelaya, en un ambiente tenso, con un llamado de la resistencia a la abstención, que convenció a una fracción del electorado aunque en un porcentaje modesto. ${ }^{51} \mathrm{Ya}$ antes, la presidencial de 2005 había marcado el menor registro histórico. Por lo tanto, más que un accidente, la abstención de 2009 se inscribió en una tendencia declinante, al punto de convertirse en una pieza clave de las elecciones. La presidencial de 2013 revirtió el declive con un repunte de hasta $61.1 \%$. Es pronto para indicar si se trata de una inflexión, una pausa en una ruta descendente o la estabilización de una pauta de asistencia que fluctuaría alrededor de 50\%-60\%. En tres décadas, Honduras ha perdido aproximadamente 25 puntos de participación, como ilustra el gráfico 1.

\section{Gráfico 1}

Evolución de la participación electoral en Honduras (1985-2013)

\footnotetext{
${ }^{50}$ Instituto Nacional Demócrata, Diagnóstico al censo electoral, Tegucigalpa, NDI-Hagamos Democracia, 2012, pp. 23-28.

${ }^{51}$ Seligson, Mitchell (coord.), Cultura política de la democracia en Honduras 2010, Tegucigalpa, Vanderbilt University, Hagamos Democracia, FOPRIDEH, 2011, p. 165.
} 
Este obra forma parte del acervo de la Biblioteca Jurídica Virtual del Instituto de Investigaciones Jurídicas de la UNAM www.juridicas.unam.mx



El descenso se explica por cuestiones técnicas relacionadas con la lenta actualización del censo electoral, y la excede, pues responde también al distanciamiento ciudadano con la estructura institucional, la pérdida de confianza en las elecciones como eje ordenador de la vida colectiva, la insatisfacción con los resultados de la democracia, el desengaño con los partidos y el balance de los gobiernos, y por la extensión de la violencia.

Parte de la caída tiene una causa estadística, corresponde a una "abstención artificial" por la deficiente depuración de los fallecidos del censo, fruto de la escasa cultura registral de fallecimientos. Inconveniente que tampoco pudo ser subsanado con la renovación de la tarjeta de identidad que debía darse a partir de 2006, cuando vencían los documentos emitidos en $1996 ;{ }^{52}$ hasta la presidencial de 2013 , en cada oportunidad se prorrogó la vigencia de las tarjetas, puesto que 300.000 muertos figurarían en el padrón. ${ }^{53}$ Cualquiera sea la cifra exacta, se incrementa y lastra cada vez de manera más fuerte (en una situación extrema, el censo podría contar con más inscritos que personas en edad para votar, como en El Salvador). Algo similar puede señalarse con respecto a los emigrantes a Estados Unidos, Canadá, España y México, los principales puntos de destino. Sólo quienes viven en Estados Unidos tienen la oportunidad de votar pero las

\footnotetext{
${ }^{52}$ Mirador electoral, Informe elecciones primarias en Honduras 2008, Tegucigalpa, Mirador electoral, 2009, p. 25.

${ }^{53}$ Instituto Nacional Demócrata, op. cit., p. 20.
} 
Este obra forma parte del acervo de la Biblioteca Jurídica Virtual del Instituto de Investigaciones Jurídicas de la UNAM

cifras son mínimas, por razones políticas, técnicas y logísticas. En 2013, de 46331 inscritos, sufragaron 3096. El liderazgo político e institucional, ${ }^{54}$ incluso asociativo, ${ }^{55}$ detiene el análisis en este punto: es un tópico convenido achacar tan elevada abstención a la limitada actualización del censo al "millón" de hondureños en Estados Unidos. El argumento minimiza la erosionada capacidad de integración y movilización de los procesos electorales.

Los hondureños han perdido confianza en algunas funciones democráticas y ciudadanas de las elecciones, dudan de la limpieza de los procesos y de la utilidad del voto. Según el Latinobarómetro de 2008 y 2009, la convicción de que lo más efectivo para cambiar las cosas es el voto, la compartía el $45 \%$ de los hondureños, relegados al último lugar en América Latina, lejos de la media (59\%) y 58\% cree que el voto puede cambiar las cosas en el futuro, por debajo de la media (64\%). Creencias que son sólo una dimensión del escepticismo con la democracia. En el periodo (2005-2013), el apoyo a la democracia fue de $53.5 \%$ para una media continental de $57 \%$ y la satisfacción de apenas $28.4 \%$ frente al promedio de $38.6 \%$. La calidad de la democracia permanece en estándares bajos: en ningún año del siglo XXI, el índice de desarrollo democrático alcanzó el promedio latinoamericano, con un puntaje de 3.7-10 en el periodo (20022013), y figuró en el onceavo puesto sobre $18 .^{56}$

Datos que impiden interpretar la elevada abstención como signo de conformidad con el sistema, de aprobación implícita de las políticas gubernamentales o de plácida indiferencia ante el relevo de partidos que conservarían las orientaciones. En Honduras, la abstención y la comodidad democrática no van aparejadas. Sectores crecientes se distanciaron del bipartidismo, de manera discreta a través de la abstención, luego de manera explícita, buscando otras opciones en los comicios de 2013, como ilustra el gráfico 2.

\section{Gráfico 2}

Distribución de los inscritos en el censo. Elecciones presidenciales

\footnotetext{
${ }^{54}$ Taylor-Robinson, Michelle, op. cit., p. 370.

${ }^{55}$ Cfr. Cáritas, Hacia procesos electorales más democráticos y transparentes, Tegucigalpa, Cáritas-Impactos, 2014, p. 17.

${ }^{56}$ Polilat-Fundación Konrad Adenauer, Índice de desarrollo democrático de América Latina 2013, Montevideo, Polilat-Fundación Konrad Adenauer, 2013, p. 13.
} 
Este obra forma parte del acervo de la Biblioteca Jurídica Virtual del Instituto de Investigaciones Jurídicas de la UNAM www.juridicas.unam.mx

de Honduras 1981-2013

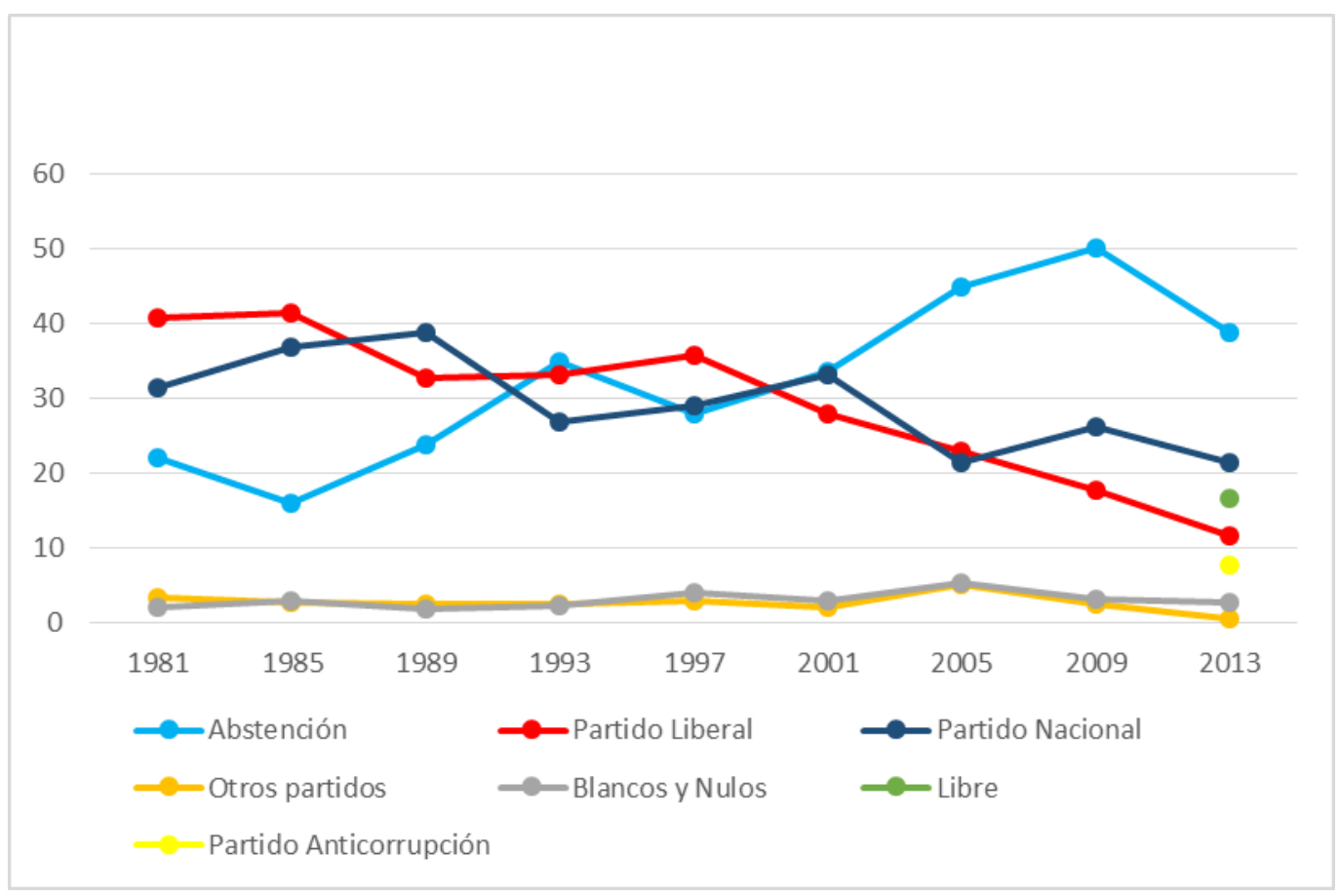

El predominio del bipartidismo, inalterado entre 1981-2009, con alrededor del 95\% de los sufragios válidos ocultó el peso creciente de la abstención, el alejamiento silencioso de franjas cada vez más importantes del electorado. Apenas había crujidos leves en el campo parlamentario, en el cual los partidos minoritarios lograron brechas: en 2009, el PDC, PINU y UD lograron la inédita cifra de 12 escaños, casi un 10\%; o señales del lado de los votos blancos y nulos que tuvieron sus puntos altos en 2005 y 2009. Progresivamente, los votantes del PN y del PL representan fracciones cada vez más exiguas del conjunto de inscritos, en el inicio de la democracia, ambos, por separado superaban a los abstencionistas; en 1993, por separado fueron superados por los abstencionistas; en 2009, juntos pesaban menos que los ausentes.

Retomando la distinción de Albert Hirschmann, ${ }^{57}$ hasta la presidencial de 2013, grupos significativos optaron por la "salida", es decir, la abstención e incluso la "salida" puede interpretarse en términos más literales con la emigración, convertida en un "escape a la situación de violencia, inseguridad e incertidumbre"; ${ }^{\prime 58}$ se mostraron poco dispuestos a la

\footnotetext{
${ }^{57}$ Hirschmann, Albert, Exit, Voice, Loyalty, Harvard U. P., 1971.

${ }^{58}$ Spada, Antonella, "Honduras: de la zona de riesgo al golpe de Estado", en PNUD-PAPEP, Honduras: el desafío de construir una salida a la crisis, Tegucigalpa, PNUD-PAPEP, 2012, p. 57.
} 
Este obra forma parte del acervo de la Biblioteca Jurídica Virtual del Instituto de Investigaciones Jurídicas de la UNAM

"lealtad" con los dos partidos históricos. Tampoco alzaron la "voz", ya sea respaldando a los partidos minoritarios, percibidos como funcionales al sistema, o integrando formas activas de movilización o protesta. La movilización en las calles que provocó la crisis de 2009 se apaciguó después del Acuerdo de Cartagena que permitió el retorno de Zelaya y la transformación de la Resistencia en un partido (2011). Se confirmó la frágil capacidad de acción pública de la sociedad. Por su parte, el conflicto social tiende a estar focalizado. Por categorías, se centra en empleados públicos como el magisterio o el personal de salud; desde el punto de vista geográfico, en el conflicto de tierras en el Bajo Aguán (departamento de Colón) ${ }^{59}$ con decenas de muertos, ${ }^{60}$ víctimas del enfrentamiento larvado entre grandes propietarios y movimientos campesinos, con un alto costo en derechos humanos. ${ }^{61}$

Esa "salida" se alimentó por motivos políticos. La aplicación de la línea económica liberal retrajo a electores nacionalistas luego del gobierno de Callejas y el mantenimiento de esas orientaciones desencantó a la base liberal después de las administraciones de Reina y Flores. En general, en América Latina, participación electoral y las reformas económicas liberales tendieron a ir en sentidos opuestos. ${ }^{62}$ La economía creció modestamente (el ingreso per cápita anual disminuyó 1.2\% entre 1980-1990, creció 1.1\% entre 1990-2008, sólo por encima de Nicaragua) se volvió dependiente de las remesas, principal fuente de divisas, y desencantó a la población. ${ }^{63}$ La tranquila alternancia de gobiernos liberales y nacionalistas limó las diferencias entre ambos y restó dramatismo a las contiendas electorales que esbozaban menos proyectos ideológicos o programas de gobierno contrapuestos que enfrentamientos entre las personalidades de los candidatos.

\footnotetext{
${ }^{59}$ Sosa, Eugenio, “La conflictividad social: encuentros y desencuentros entre actores políticos y sociales y el Estado", en CEDOH, Conflictividad, Estado y sociedad, Tegucigalpa, CEDOH, 2013, pp. 68-71.

${ }^{60}$ Observatorio de derechos humanos del Aguán, Informe estadístico de muertes violentas relacionadas al conflicto de tierras en el Bajo Aguán 2008-2013, Tegucigalpa, Observatorio de derechos humanos del Aguán, 2014, p. 13.

${ }^{61}$ Human Rights Watch, Aquí no hay investigaciones, Estados Unidos, Human Rights Watch, 2014, p. 80.

${ }^{62}$ Lavezzolo, Sebastián, “Adversidad económica y participación electoral en América Latina, 1980-2000", Ponencia presentada en el XII Encuentro de latinoamericanistas españoles, Santander, 2006.

${ }^{63}$ Cfr. Lehoucq, Fabrice, “La democratización en Centroamérica desde sus guerras civiles: fortalezas y debilidades", Revista de Derecho Electoral (16), julio-diciembre de 2013, pp. 29-32.
} 
Este obra forma parte del acervo de la Biblioteca Jurídica Virtual del Instituto de Investigaciones Jurídicas de la UNAM

Las políticas públicas mostraron continuidades que restaron nitidez a las distinciones partidarias, lo que permeó al conjunto de la sociedad, al punto que un dato sorprendente fuera la similitud en las escalas de valores, expectativas y prioridades de los electores liberales y nacionalistas. ${ }^{64} \mathrm{El}$ liderazgo político también exhibió su vulnerabilidad a la hora de responder de los desafíos imprevistos. El huracán Mitch (1998) activó a la sociedad civil, generó demandas de inclusión y transparencia que a los partidos les costó entender y se debilitó "su calidad de intérpretes, gestores y procesadores de las demandas sociales". ${ }^{65}$ Los gobiernos se hallaron igualmente desarmados ante la vertiginosa espiral de violencia, cuyo indicador central, la tasa de homicidios por 100.000 habitantes, trepó de alrededor de 50 a más de 80 entre 2000$2010{ }^{66}$ Honduras se convirtió en uno de los países más violentos del mundo.

Asimismo, se siente la corrupción en la administración pública como extendida, crónica e impune. Según los datos de Transparencia de 2013, en una escala de 0 a 10, el país obtuvo 2.6, quedando en el lugar 140 sobre 175 países o territorios. ${ }^{67}$ La percepción daña el juicio ciudadano sobre las instituciones, actores, dirigentes y lo aleja del juego político: investigaciones han establecido un vínculo entre ser víctima de la corrupción y la pérdida de confianza en las instituciones.

De manera más reciente, la participación electoral está afectada por la violencia. Se contrapone el norte abstencionista, una de las zonas más peligrosas de América Central, ${ }^{68}$ y por ello, del mundo, y la franja occidental-sureña, más participativa y con mejores indicadores de seguridad. A diferencia de los impactos de la violencia política, existen pocos estudios sobre las consecuencias de la violencia ligada al crimen organizado y la delincuencia común sobre la participación política. Parte de la explicación de la brecha en las tasas de participación entre la América del sur y la Central, puede radicar en los disímiles niveles de violencia, pasados y presentes de ambas zonas.

\footnotetext{
${ }^{64}$ Instituto Nacional Demócrata, op. cit., p. 38.

${ }^{65}$ Meza, Víctor, Honduras: crisis política y solución democrática (documento de análisis 97), Tegucigalpa, CEDOH, 2012, p. 9.

${ }^{66}$ Programa estado de la nación, Resumen estado de la región, San José, Programa estado de la nación, 2011, p. 27.

${ }^{67}$ Los datos de Transparencia Internacional se encuentran en, www.transparencia.org.

${ }^{68}$ Programa estado de la nación, op. cit., p. 35.
} 
Este obra forma parte del acervo de la Biblioteca Jurídica Virtual del Instituto de Investigaciones Jurídicas de la UNAM

En América Latina, la participación electoral de las presidenciales (2011-2014) y la tasa de homicidios presentan una alta correlación inversa, de -0.71. En Honduras, la correlación departamental fue de -0.52 para los comicios de 2009 y de -0.42 para los de 2013, suficiente como para abrir un expediente sino un debate.

Hoy la violencia emerge con nuevo rostro, no desde el Estado o contra el Estado, tampoco con contenidos políticos o ideológicos, como sucedió en las guerras civiles centroamericanas. Sin embargo, sus efectos limitan la participación y el ejercicio libre del sufragio. Por un lado, el narcotráfico se implantó, en particular en las costas y áreas rurales centroamericanas de escasa presencia estatal, utilizadas como lugar de tránsito de la droga llevada desde el sur hacia el norte del continente; asimismo, recicló ganancias con el lavado de activos. Cuando el narcotráfico se instala en un territorio para controlarlo, socava las bases de la comunidad, impone el miedo o la complicidad, recorta la competitividad y el pluralismo de la vida política, distorsiona las campañas electorales. Candidatos ajenos a esas estructuras son eliminados o acosados para retirarse de la carrera; si hay algún grado de pluralismo, el desequilibrio de los recursos inclina la balanza del lado de los candidatos coludidos con el crimen organizado. Regiones periféricas de Guatemala y Honduras, convertidas en corredores de la droga, sufren hoy estos escenarios. ${ }^{69}$ Este fenómeno tiene más visibilidad a nivel local que presidencial, y afecta igual a los estados de México. En estas condiciones, asistir a votar pierde sentido para amplias franjas del electorado o, por el contrario, se convierte en una pesada obligación sin auténtica opción de elegir.

En 2013 en El Paraíso (Copán), un municipio con una reputación ensombrecida, los miembros de mesa de varios partidos debieron fugar la presencia de observadores y testigos imparciales quedó vetada. ${ }^{70}$ La participación reportada, sin embargo, alcanzó $84.5 \%$, casi 25 puntos por encima del promedio nacional y una quincena arriba del porcentaje departamental, y al candidato para alcalde superó el $90 \%$. Sin el dramatismo de las cifras, probablemente por las características más urbanas, en el municipio de Yoro —Arnaldo Urbina - alcalde reelegido en 2013 y detenido al año siguiente bajo cargos de

\footnotetext{
${ }^{69}$ Adenauer Stiftung, Konrad, La red, seguridad y crimen organizado transnacional, Guatemala, Konrad Adenauer Stiftung, La Red, 2011, p. 49.

${ }^{70}$ Meza, Víctor (coord.), Honduras 2013: proceso electoral, financiamiento y transparencia, Tegucigalpa: CEDOH-NDI, 2014, pp. 108 y 109.
} 
Este obra forma parte del acervo de la Biblioteca Jurídica Virtual del Instituto de Investigaciones Jurídicas de la UNAM

asociación con el narcotráfico, reunió una docena de puntos adicionales con respecto al candidato presidencial de su partido y acumuló $63.6 \%$ de los sufragios. Según Marvín Ponce, exdiputado y asesor del presidente Hernández, unos 35 alcaldes y vicealcaldes estarían ligados con el narcotráfico. ${ }^{71}$ El estudio de los resultados atípicos en la participación y en la distribución de las preferencias se convierte ya en una necesidad para detectar indicios de situaciones anómalas.

Por otro lado, la violencia del crimen organizado y la común con su rostro duro de secuestros, extorsiones, asesinatos, ejecutados por las maras, mina igualmente la participación. La violencia descontrolada no sólo conduce al "hombre a actuar como un lobo para el hombre", destruye el tejido de la vida colectiva, rompe la confianza en los otros y genera un repliegue inmediato sobre las esferas más íntimas. Allá donde ella impera, se contraen todas las formas de participación e intervención en los espacios colectivos, así sea por algo tan elemental y básico como el temor a circular por las calles, atravesar un área controlada por un mara que no identifica a uno como residente, ser víctima de fuego cruzado o simplemente ser asaltado en el transporte público. ${ }^{72} \mathrm{Con}$ el paso del tiempo, la gente teme o se desinteresa de comprometerse con un partido, afiliarse a un sindicato, colaborar con una asociación o un patronato, expresar sus opciones. A la larga, hasta se pierde la voluntad de votar, que implica hacerse miembro de la comunidad de ciudadanos y definir el destino colectivo. Como en cualquier entorno altamente agresivo, el objetivo es pasar discreto, disminuir los riesgos y exponerse lo menos posible.

En otras palabras, la imposibilidad del Estado para imponer su autoridad y la de la ley restringe la inclusión política de la democracia de sectores más o menos amplios: áreas golpeadas por el narcotráfico y barrios secuestrados por la delincuencia ordinaria se encuentran en la primera línea. Este escenario de Tegucigalpa o San Pedro Sula es igualmente visible en Ciudad de Guatemala o San Salvador. En los barrios peligrosos, el organismo electoral se somete al pago de un "impuesto de guerra" para realizar las pruebas de transmisión de datos, la policía se mantiene a distancia, los partidos realizan,

\footnotetext{
71 “Marvin Ponce dijo que hay unos 35 narco-alcaldes" en Honduprensa, 8 de octubre de 2014.

${ }^{72}$ Según los datos de una investigación con el apoyo del Banco Centroamericano de Integración Económica: 100\% de los pasajeros del transporte público de Tegucigalpa fue asaltado en el transcurso del último año, “100\% de pasajeros han sido asaltados", El Heraldo, 28 de septiembre de 2012.
} 
Este obra forma parte del acervo de la Biblioteca Jurídica Virtual del Instituto de Investigaciones Jurídicas de la UNAM

en el mejor de los casos, un proselitismo fugaz, la observación electoral local sufre para encontrar voluntarios para cubrir los recintos ${ }^{73}$ y la observación internacional evita exponer a sus integrantes.

La geografía de la participación distingue tres áreas. La abstención acentuada cubre la costa atlántica, incluyendo las Islas de la Bahía, y tiene como pivote las ciudades de San Pedro Sula, Choloma y La Ceiba. La apatía se extiende a los departamentos próximos de Gracias a Dios y Yoro; en una situación intermedia, se ubica en el corazón central del país, alrededor de Tegucigalpa, con extensiones hacia Comayagua y Olancho. El área participativa cubre la franja sud-occidental, desde Copán y Ocotepeque hasta Choluteca. Existe una fuerte continuidad, la correlación de la participación entre los comicios de 1985 y 2009 en la escala departamental, es de 0.79.

Sin embargo, las regiones atrasadas - rurales- participan más y ofrecen una paradoja. De manera opuesta a la vinculación habitual entre progreso socioeconómico y participación, frecuente en América Latina y conforme a la teoría de la modernización política, en Honduras se asocia menor desarrollo humano, en especial, los bajos desempeños educativos, y una alta asistencia electoral. ${ }^{74}$ Para los comicios de 2013 , la correlación departamental entre el índice de desarrollo humano (IDH) y la participación tuvo un valor de -0.76 .

Las pistas explicativas, acumulativas antes que alternativas, apuntan a una mayor efectividad del clientelismo en regiones con alta concentración de electores en condición de pobreza y baja densidad estatal; ${ }^{75}$ así como la mejor resistencia de las identidades y lealtades partidarias en ambientes de cambios socioeconómicos y culturales lentos; la percepción del voto como una obligación colectiva en espacios de convivencia tradicional que facilitan la socialización, la confianza interpersonal y las relaciones comunitarias. ${ }^{76}$

\footnotetext{
${ }^{73}$ En los comicios de 2012 y 2013, el consorcio Hagamos Democracia no consiguió cubrir ciertos puntos de la muestra en Tegucigalpa y San Pedro Sula por la negativa de los voluntarios de ir a los barrios más peligrosos y la complicación de reclutamiento en la misma colonia.

${ }^{74}$ Cálix, Álvaro y Sonnleitener, Willibald, op. cit., pp. 22 y 25.

${ }^{75}$ Meléndez, Carlos, Honduras elecciones 2013: compra de votos y democracia, Tegucigalpa, CEDOH-NDI, 2014, pp. 18 y 19.

${ }^{76}$ Programa de las Naciones Unidas para el Desarrollo, Resumen del Informe de desarrollo humano Honduras 2006, Tegucigalpa, PNUD, 2006, p. 14.
} 
Este obra forma parte del acervo de la Biblioteca Jurídica Virtual del Instituto de Investigaciones Jurídicas de la UNAM

En cambio, en el norte, urbano, industrial, comerciante, exportador, próspero y tierra de inmigrantes, el clientelismo rendiría menos, los ciudadanos tendrían más independencia con respecto a la política, ${ }^{77}$ las elecciones se inscribirían menos en una dinámica tradicional de socialización comunitaria.

La brecha entre zonas participativas y abstencionistas se amplió. En 1985, la separación entre los dos departamentos extremos fue de 12.3 puntos a pesar de que el promedio nacional rebasaba 85\%; en 2013, de 25.6 puntos entre Lempira y Atlántida (de 24.7 puntos en 2009, para los departamentos extremos). La caída general de la participación fue un desplome en la costa atlántica, lo que acentúa la correlación entre abstención y mayor índice de desarrollo humano. Los departamentos dinámicos parecen esperar cada vez menos de los partidos, las elecciones y la política, concentran sus energías en su propio desarrollo o en lidiar con el drama de la inseguridad. Asimismo, esa geografía tiene resonancias políticas: el liberalismo se implanta en las zonas abstencionistas, el nacionalismo en las participativas. El retroceso liberal de principios del siglo XXI no es ajeno a la mengua de la participación en sus bastiones, igualmente, excede la casualidad que en 2013 el abstencionista departamento de Cortés fuera también el centro del flamante Partido Anti Corrupción (PAC).

En las principales ciudades se verifica mejor el lazo habitual entre prosperidad y participación. Por ejemplo, en 2013, para una media de 63.4\% en Tegucigalpa, la participación bordeó $68 \%$ en los barrios privilegiados (recintos de votación de la Universidad Nacional Autónoma, Instituto San Miguel, Complejo Simón Azcona, etcétera). Los grupos con alto nivel educativo y de ingreso están familiarizados con el juego político, al cual ofrecen numerosos cuadros, cuando no presidentes. Por el contrario, en los barrios populares, enfrentados a condiciones de vida difíciles, de acceso a servicios públicos, de seguridad, con presencia de inmigrantes rurales o de pequeñas ciudades, se reduce la asistencia. A diferencia de lo que puede ocurrir en los departamentos occidentales, altamente participativos y de escaso desarrollo, donde se afincan fuertes redes de los partidos poco sometidas a la presión de novedades que alteran los comportamientos tradicionales; en los barrios pobres les cuesta organizarse y hacen frente a un ánimo menos predispuesto de los nuevos citadinos, que sufren el desencanto entre sus expectativas de instalación ante la realidad y la visibilidad de las desigualdades.

\footnotetext{
${ }^{77}$ Es conocida la expresión: “Tegucigalpa hace política, San Pedro Sula trabaja y La Ceiba baila”.
} 
Este obra forma parte del acervo de la Biblioteca Jurídica Virtual del Instituto de Investigaciones Jurídicas de la UNAM

Por último, desde el punto de vista sociodemográfico, la participación mezcla perfiles habituales y atípicos. En 2009, con base en los datos completos de los listados, ${ }^{78}$ la participación creció progresivamente con la edad, alcanzó el tope alrededor de los 60 años y bajó en la población joven, dejando de lado a los debutantes, bastante entusiastas. Las mujeres aventajaron ligeramente a los hombres, como ocurre con mayor frecuencia en América Latina, en especial entre las jóvenes y adultas, ya que entre las mayores de 60 años prevalecen en pautas más tradicionales de comportamiento y la asistencia femenina declina más rápido que la masculina. Una encuesta postelectoral de $2013^{79}$ mostró que las personas sin o con pocos ingresos sufragaron más. El dato es compatible con la verificación de una relación inversa en las ciudades pues es la alta asistencia de electores rurales de regiones pobres que, a nivel nacional, coloca la mayor participación del lado de los ciudadanos con ingresos limitados. Aquellas sin identificación partidaria sufragaron en una proporción bastante menor que quienes si se sentían próximos a un partido. Si ese aspecto es común en sí mismo, contrariamente a lo que sucede en numerosos países, la ausencia de identificación partidaria crece en los sectores que reivindican el rostro de la modernidad: favorecidos, educados y jóvenes. Desconfiados de los partidos y escépticos con la limpieza de los procesos electorales, navegan insatisfechos en la democracia y su principal símbolo son las elecciones.

\section{CIUDADANÍA, PARTIDOS Y ELECCIONES}

En una perspectiva histórica, desde mediados de siglo, se observa la modernización y la democratización de la sociedad, las instituciones y el sistema político hondureño. Los comicios reflejan una sociedad más abierta, integrada y democrática. Del universo monopolizado por los hombres, hoy, el censo tiene un componente femenino mayoritario y las mujeres acuden en mayor proporción a sufragar. El Estado realiza esfuerzos por documentar poblaciones históricamente marginadas e incorporarlas en la vida política institucionalizada. El censo acoge a más de $90 \%$ de la población en edad de inscribirse. El perfil de los representantes, todavía mayoritariamente hombres de clases favorecidas, se diversifica, aunque más lentamente, como en un eco débil y atrasado del perfil de los inscritos.

\footnotetext{
${ }^{78}$ Gélineau, Francois y Garzón, José Ángel, “Participación electoral en América Central”, investigación preparada para la Organización de Estados Americanos.

${ }^{79}$ Borge y asociados, op. cit.
} 
Este obra forma parte del acervo de la Biblioteca Jurídica Virtual del Instituto de Investigaciones Jurídicas de la UNAM

Las elecciones ayer dominadas por el gobierno, destinadas a asegurar la reelección oficialista frente a una oposición amenazada, tienen una regularidad temporal y, grados de pluralismo y transparencia sin precedentes, capaces de convertir la alternancia en una evidencia. La libertad en las campañas es amplia, si bien, quedan desafíos en materia de equidad en la competencia y en el respeto a las frágiles disposiciones que reglamentan el financiamiento de la política. En cierto sentido, la equidad se encontraba asegurada entre los dos partidos históricos, capaces de recurrir a importantes $y$, probablemente, equivalentes recursos privados e incluso, aún contraviniendo las normas, públicos (el uso de los bienes del Estado, como vehículos, en las campañas es moneda corriente y socialmente tolerada). Fuera de ese espacio, el desequilibrio es manifiesto en desmedro de los otros partidos o candidatos.

El organismo electoral dejó de subordinarse al Poder Ejecutivo para transitar hacia un esquema de control de los partidos, que buscaron en la vigilancia recíproca la garantía de la limpieza de los comicios. Luego se dieron pasos hacia la conformación de un TSE más independiente, garante de una jornada electoral honesta, abierto a los controles, la transparencia, la rendición de cuentas, pero aún persiste un bemol entre las disposiciones apartidistas y las prácticas de los partidos que se resisten a perder el control del órgano electoral. Asimismo, los progresos en la profesionalización han sido más frágiles que los alcanzados por otros tribunales centroamericanos y la faceta jurisdiccional se halla en una fase embrionaria por la fragilidad de las líneas jurisprudenciales o la demora en la resolución de los casos planteados.

Esos cambios - fundamentales en una perspectiva histórica - han encontrado sus límites, y la democracia, las elecciones y el sistema partidario parecen encontrarse con una savia empobrecida. Sin reiterar los argumentos y los datos ya anotados, resulta necesario interrogarse sobre el vínculo de los partidos con la ciudadanía y el electorado.

Honduras ha perdido casi 25 puntos de participación electoral entre el retorno a la democracia y los comicios de 2013, aunque éstos marcaron un repunte con respecto a la elección previa. Corresponde interrogarse sobre el posicionamiento de los partidos frente al alza de la abstención.

Aún después de la presidencial de 2009, la abstención inquietaba poco y tuvo efectos limitados sobre las organizaciones. La inadecuada depuración de fallecidos y el "millón" de hondureños en Estados Unidos se citaban como explicación de la abstención. Por 
Este obra forma parte del acervo de la Biblioteca Jurídica Virtual del Instituto de Investigaciones Jurídicas de la UNAM

fundada que sea, ella no agota el problema. También se repetía que la presidencial de 2009 fue la más votada, cierto en términos absolutos pero falaz en porcentaje, que es sin duda para estos casos, el parámetro idóneo de evaluación. Esta minimización se vinculaba probablemente con el hecho de que la abstención no alteraba las pautas de la distribución de los votos. Tampoco la presidencial de 2013 ahondó la reflexión, sin duda, por el mejoramiento de la participación y por la continuidad del PN en el poder.

De esta manera, se produjo una progresiva desalineación frente a los partidos tradicionales, ${ }^{80}$ aunque como el retiro de los ciudadanos no favorecía o perjudicaba a ninguna de las dos grandes fuerzas ni alteraba el bipartidismo, nacionalistas y liberales se desentendieron del asunto, tanto más que esa abstención es probablemente funcional con las bases de la vida política en Honduras. O como señala Giovanni Sartori, el desencanto y la desilusión de los ciudadanos llevaron a la apatía y "el ciudadano apático hizo muy fácil la política". ${ }^{81}$

El Estado funciona con una marcada lógica partidista, "un elemento constitutivo de la secular cultura administrativa que ha dominado el imaginario de los líderes de los partidos". ${ }^{82}$ El partido ganador copa el aparato público dependiente del Poder Ejecutivo: ministerios, empresas públicas, entidades de servicio público, con una renovación extensa de los funcionarios. A veces, la lógica incluso se acota y el reparto ni siquiera es partidista sino dominado por las corrientes vinculadas a los candidatos presidenciales que compitieron en las primarias. Los beneficiarios de los puestos son militantes y activistas del nuevo oficialismo. La exigencia para que ocupen cargos es abierta, públicamente defendida desde los altos puestos partidistas: el proselitismo es carta para acceder a funciones públicas. ${ }^{83}$ Incluso, la administración acoge no sólo a los nuevos funcionarios que ejercerán labores sino a los "paracaidistas", personas que ingresan en planillas, cobran el sueldo sin trabajar en la institución pues están dedicadas a funciones

\footnotetext{
${ }^{80}$ Vanderbilt University, Cultura política de la democracia en Honduras y en las Américas 2012, Tegucigalpa, Vanderbilt University, 2012, pp. 173-175.

${ }^{81}$ Sartori, Giovanni, Ingeniería constitucional comparada, México, Fondo de Cultura Económica, 2010.

${ }^{82}$ Posas, Mario, op. cit., p. 118.

${ }^{83}$ A modo de ejemplo, el alcalde de Tegucigalpa y presidente del PN, Ricardo Álvarez lamentaba lo siguiente: "varios líderes, lideresas, dirigentes activistas siguen esperando su espacio. Se ganaron con el duro trabajo de dos elecciones y muchos ministros siguen sin abrir las puertas", Hondudiario, 11 de mayo de 2011.
} 
Este obra forma parte del acervo de la Biblioteca Jurídica Virtual del Instituto de Investigaciones Jurídicas de la UNAM

partidistas o simplemente actividades privadas pero que obtienen el privilegio por servicios prestados o por prestar. Pueden sumar centenares de personas, gravando los presupuestos institucionales. Esa práctica es aceptada como una costumbre, aunque estigmatizada en público. ${ }^{84}$

La obtención de los puestos se vincula con labores proselitistas o, cuando menos, con la evidente adhesión al partido al haber sufragado en los comicios internos de la organización. En efecto, las primarias organizadas por el TSE se efectúan con padrón abierto y simultáneamente para el PN y PL (en 2012, por primera vez, la primaria contó con tres partidos, ya que se añadió Libertad y Refundación, Libre), sin embargo, en mesas separadas. Esto implica que si un ciudadano acude a votar queda inmediatamente registrado en las listas manejadas por el partido y muchas veces revisadas antes de asignar cargos públicos. En contrapartida, los empleados públicos son sometidos a un régimen de aportes, en teoría voluntario, obligatorio en la práctica, y la negativa al aporte puede concluir en el despido. ${ }^{85}$ En ese esquema, una elección en la cual se achica el número de votantes no plantea inconvenientes, simplifica el complejo reparto de los espacios en la administración pública nacional y local.

Al margen del Poder Ejecutivo, en el Poder Judicial la pauta de distribución es bipartidista: los cargos se dividen entre nacionalistas y liberales, con una ligera ventaja para el partido gobernante de turno, y los partidos minoritarios consiguen eventualmente butacas marginales, a veces decisivas para inclinar la balanza. En ciertas oportunidades, los acuerdos se realizan menos entre los partidos que entre fracciones que juntas alcanzan las mayorías necesarias. Esa pauta para designaciones judiciales o en instituciones en principio apartidistas - como el TSE o el RNP — fue perceptible desde el inicio de la democracia, como ilustró el acuerdo entre las bancadas afines al presidente liberal José Azcona y a Callejas, líder de la oposición. ${ }^{86}$ Las normas destinadas a evitar las cuotas partidarias en la CSJ, como el involucramiento de la sociedad civil,

\footnotetext{
${ }^{84}$ Cfr. "No habrá paracaidistas en este gobierno: JOH", El Heraldo, 18 de mayo de 2014 (JOH es la sigla de Juan Orlando Hernández).

85 "Gobierno cobra "impuesto de guerra", El Heraldo, 15 de abril de 2013. En 2013, en la circular remitida por el PN citada en la noticia, el porcentaje de aportes se escalonaba entre 3.5\% (para salarios menores a 750 dólares, aproximadamente) hasta 11\%, para salarios superiores a aproximadamente 2.500 dólares.

${ }^{86}$ Molina, Guillermo, op. cit.
} 
Este obra forma parte del acervo de la Biblioteca Jurídica Virtual del Instituto de Investigaciones Jurídicas de la UNAM

aprobadas con el mismo ánimo que la reforma en la composición del TSE carecieron de resultados efectivos. ${ }^{87}$

Se trata de una situación paradójica: los partidos aprueban disposiciones para limitar su intervención pero se desdicen en los hechos. Este comportamiento se explica probablemente por el deseo de complacer a grupos dinámicos de la sociedad civil o de la cooperación internacional que ejercen una presión moral, aunque sin voluntad real que la concesión se traduzca en actos. También puede provenir de la mutua desconfianza entre partidos, y el escepticismo que en una sociedad tan teñida por el bipartidismo existan personalidades auténticamente independientes, así sea porque un individuo proviene de una familia más identificada con uno u otro partido.

Las campañas tienen un sello personalista y de prebendas. De arriba hacia abajo los candidatos son la llave de acceso a los cargos y beneficios públicos. Las candidaturas son ante todo proyectos personales o de clanes, rara vez se diferencian las unas de las otras por doctrina o matices ideológicos. Hasta los nombres de los movimientos lo subraya. Por ejemplo, en 2004 en las internas liberales compitieron, entre otros, el "Movimiento Esperanza Liberal" (la sigla MEL correspondía exactamente al diminutivo con el cual es conocido Manuel Zelaya), el "movimiento jaimista" de Jaime Rosenthal (en 2012, su hijo Yani creó el "movimiento yanista"), el "Movimiento Marlon Lara" de Marlon Lara. Evidentemente, esta tendencia no es exclusiva del liberalismo ni de esa elección.

Los gastos de la campaña y las prebendas provienen de los recursos propios de los candidatos, lo que requiere un sólido capital familiar o personal; de aportes privados, lo que implica vínculos con el empresariado que suele organizar poderosos conglomerados que abarcan y articulan numerosos sectores; de fondos públicos, entre los cuales destacan los subsidios que manejan los parlamentarios, con pocas reglas y bastante opacidad, y refuerzan la posición de los elegidos; de los bienes públicos, además del uso del tiempo de funcionarios, lo que favorece a quienes pueden dar instrucciones en este sentido; del financiamiento estatal que sirve prioritariamente a las direcciones nacionales; eventualmente de contribuciones de grupos ilegales. El manejo de las prebendas requiere conexiones con las estructuras medias y bajas del partido, vinculadas con las redes locales. Los alcaldes, el eslabón pequeño de la cadena, reciben

\footnotetext{
${ }^{87}$ Comisión Internacional de Juristas, La independencia del Poder Judicial en Honduras (2004-2013), Tegucigalpa, Comisión Internacional de Juristas, 2014, p. 27.
} 
Este obra forma parte del acervo de la Biblioteca Jurídica Virtual del Instituto de Investigaciones Jurídicas de la UNAM

recursos de candidatos presidenciales o legislativos con la promesa de movilizar las bases, lo que también puede implicar entregar o compartir recursos con los patronatos de los barrios y colonias.

El juego económico tiene poca claridad. Las normas sobre el financiamiento político son frágiles, con escasas rendiciones de cuenta, mínimos controles, sanciones esporádicas o ausentes, y desinterés ciudadano por el tema. ${ }^{88}$ Este cuadro tiene rasgos más críticos en las primarias. En ellas, rivalizan movimientos o corrientes que jurídicamente apenas sí existen pues se conforman para esos comicios con escasas reglas, manejan importantes recursos en lapsos breves con minúsculos controles, y desaparecen después de la jornada electoral —con excepción del movimiento del candidato ganador que se convierte en la informal columna vertebral del partido para la presidencial-.

Los candidatos, en cualquier nivel aunque con mayor visibilidad en los ámbitos locales, buscan el apoyo popular con regalos. Ofrecen "despensas" (paquetes de alimentos básicos) en actos a los cuales se busca darles notoriedad, publicidad y difusión para mostrar el estilo solidario del candidato. La lista de obsequios es tan extensa como la imaginación de los aspirantes: fogones para preparar tortillas, ${ }^{89}$ sillas de ruedas, bolsas de agua para niños en los desfiles, entrega de piñatas en la festividad del día del niño, envío de carros cisternas con agua a barrios marginales, fardos de ropa, organización de torneos deportivos infantiles, ${ }^{90}$ atención en consultorios médicos o campañas de fumigación, ${ }^{91}$ etcétera. No se trata de un movimiento unilateral. Los ciudadanos aguardan las campañas para solicitar o exigir esos regalos que ayudan a resolver una necesidad atrasada, alcanzar bienes poco comunes en su vida cotidiana, pasar un buen

\footnotetext{
${ }^{88}$ Casco, Guillermo, "El financiamiento político en Honduras" en Gutiérrez, Pablo y Zovatto, Daniel (coords.), Financiamiento de los partidos políticos en América Latina, México, UNAM, IDEA, OEA, 2011, pp. 321-348.

${ }^{89}$ Cfr. La reivindicación del apodo “Juan Fogón” por parte de Juan Orlando Hernández que durante la campaña de primarias y generales, regaló esos fogones.

${ }^{90}$ Cfr. "El Mundial de Lizzy" organizado por Lizzy Flores desde 2006, "Mary Lizzy Flores Flake-curriculum vitae" (separata).

${ }^{91}$ Cfr. La propaganda de Marcia Villeda para la municipal de 2013 en Tegucigalpa informaba: “más de 46492 capitalinos atendidos en las clínicas médicas, capacitación y creación de 300 nuevas microempresas con 2.1 millones de capital semilla, 822 barrios y colonias fumigadas", El Heraldo, Propuestas electorales, 12 de noviembre de 2012.
} 
Este obra forma parte del acervo de la Biblioteca Jurídica Virtual del Instituto de Investigaciones Jurídicas de la UNAM

momento. Si recibir esas ayudas o bienes no garantiza el voto, la negativa de un candidato a prestarse al juego le resta posibilidades, a menos que fuera acreedor de cualidades carismáticas o de notoriedad excepcionales.

Los elegidos mantienen el estilo de acción. En efecto, hasta la legislatura cerrada en 2014, cada diputado titular recibía aproximadamente 50.000 dólares por año (un millón de lempiras), los suplentes alrededor de 20.000 dólares, del fondo social de planificación departamental, que podían usar con bastante discrecionalidad. Los utilizaban, entre otros fines, para donar insumos y accesorios agrícolas para productores, meriendas y útiles escolares para familias con hijos en la escuela, cemento para familias pobres, reparar calles; ${ }^{92}$ mantener los lazos con sus bases a través de festejos para el día de la madre, entrega de ataúdes o brigadas médicas. ${ }^{93}$ El manejo de recursos públicos bajo esta modalidad es excepcional en el ámbito parlamentario mundial y en términos prácticos implica que los diputados asumen funciones habituales de los alcaldes 0 reemplazan a los precarios servicios públicos. El voto preferente en listas abiertas, la orientación clientelista de las campañas y la disponibilidad de recursos públicos terminan orientando a los diputados hacia una visión y un comportamiento localistas en comparación con otros parlamentarios de la región. ${ }^{94}$

El recurso a las prebendas y la constitución de pequeñas clientelas es alentado por el voto preferente en listas abiertas que pone a un candidato parlamentario en feroz disputa por asegurarse un campo en el corazón o la memoria de los votantes. A manera de ejemplo, en 2012, para 23 cupos disponibles un candidato a diputado en las elecciones internas del PN por el departamento de Francisco Morazán disputó su puesto de manera directa contra otros 160 aspirantes de la misma organización. Si figuró en la lista de los elegidos para los comicios de 2013, tuvo que repetir el proselitismo para lograr la preferencia frente a más de 200 candidatos, de su partido y de los otros, nuevamente para llevarse uno de los 23 curules departamentales. En otras palabras,

\footnotetext{
${ }^{92}$ Fundación Democracia sin Fronteras, Informe de producción legislativa y manejo de recursos públicos, Tegucigalpa, Fundación Democracia sin Fronteras, 2012, pp. 32-83.

93 “Diputados pagarán, pero piden cuentas al CCEPL”, El Heraldo, 23 de mayo de 2014 (declaración del diputado liberal Marco Antonio Andino).

${ }^{94}$ Martínez, Mar, La carrera política de los parlamentarios costarricenses, salvadoreños, hondureños: selección y ambición (tesis de doctorado en la Universidad de Salamanca).
} 
Este obra forma parte del acervo de la Biblioteca Jurídica Virtual del Instituto de Investigaciones Jurídicas de la UNAM

cualquiera de los 8 diputados del PN de Morazán, elegidos en 2013, dejó en el camino a aproximadamente 350 rivales entre 2012 y 2013. Y si para distinguirse en esa multitud no alcanza una propuesta innovadora o una idea de impacto, siempre queda el recurso de la ofensiva de la sonrisa. Durante la elección de 2013, algunos candidatos a diputados en el departamento gastaron más en propaganda que los candidatos presidenciales de los partidos pequeños.

La dinámica de campañas personalistas, prebendas y clientelas se acomoda bien con un achicamiento del cuerpo electoral. Por un lado, si la población a la cual se necesita llegar es menos extensa, se limitan los de por sí elevados costos de una campaña, que además de la propagada, comprenden visitas a colonias y localidades con regalos, impresión de afiches y volantes, activación de redes de militantes y costos de la jornada electoral. En efecto, para ese día, los candidatos requieren una logística precisa para que los integrantes de la mesa - representantes de las corrientes en las primarias y de los partidos en las elecciones generales - y los fiscales del partido se desplacen a cumplir sus funciones, reciban un refrigerio y a veces un estipendio para garantizar la lealtad, además como extra, es útil ofrecer transporte a los votantes. Por otro lado, en un contexto de abstención fuerte, el valor y la importancia de una clientela electoral dispuesta a movilizarse, pesa e influye más. En un entorno marcado por fuertes niveles de identificación partidaria y bajos índices de participación, la "compra de votos" en 2009 se orientó a los electores más fieles, simplemente para asegurar que asistieran a sufragar. ${ }^{95}$ En ese sentido, muchas veces, la "compra" busca menos un intercambio inmediato, preciso entre un bien entregado y una marca en la papeleta que la creación o más a menudo el fortalecimiento de una identificación partidaria capaz de generar una preferencia de largo plazo. ${ }^{96}$

La combinación de una abstención elevada con una movilización, muchas veces, por mecanismos de prebenda y clientelas logradas con recursos del sector privado, repercute sobre la independencia de la política y la orientación de las políticas públicas. El financiamiento proviene de poderosos y limitados conglomerados que controlan

\footnotetext{
${ }^{95}$ González Ocantos, Ezequiel, Kiewiet de Jonge, Chad et al., “Compra de votos en América Central: un estudio preliminar", en Romero Ballivián, Salvador (coord.), Democracia, elecciones y ciudadanía en Honduras, p. 165.

${ }^{96}$ Meléndez, Carlos, Honduras, elecciones 2013: compra de votos y democracia, Tegucigalpa, CEDOH-NDI, 2014, p. 20.
} 
Este obra forma parte del acervo de la Biblioteca Jurídica Virtual del Instituto de Investigaciones Jurídicas de la UNAM

campos clave de la economía, y reparten sus simpatías y gastos de campaña entre los dos partidos históricos. ${ }^{97}$ En 2013, desconfiaron de Libre y le retacearon su respaldo. Estos poderes fácticos pueden recibir, a cambio, accesos privilegiados a las decisiones del Estado, adquisiciones directas de bienes o servicios sin licitación o procesos amañados, exenciones y perdones tributarios en un contexto de modesta presión fiscal (como en el resto de América Central) y facilidades para conservar oligopolios..$^{98}$ Este "capitalismo de compadres" imbrica lo económico y lo político. ${ }^{99}$ Existen reducidos incentivos para corregir desigualdades a través de instrumentos impositivos o dar fluidez a los mecanismos de libre competencia. No constituye una paradoja menor que Honduras, un país bien predispuesto hacia el capitalismo, posea numerosos mercados con un funcionamiento sesgado.

Por su parte, sectores populares y medios comprendidos o no en el juego de prebendas y clientelas, miran los resultados de la política con creciente escepticismo. De acuerdo al Latinobarómetro, en 2008 la sensación que se gobierna para los poderosos llegó a $80 \%$ en Honduras contra $70 \%$ en América Latina, la impresión que las desigualdades permanecen en democracia fue de $55 \%$ contra $48 \%$ para el promedio. Sensaciones y fríos indicadores convergen y señalan a Honduras como uno de los países más desiguales en una de las regiones ya más inequitativas del planeta. En América Latina ocupa el tercer lugar, después de Haití y Colombia. ${ }^{100}$

\section{CONCLUSIÓN: LA ELECCIÓN DE 2013 ¿LA TRANSICIÓN HISTÓRICA DEL SISTEMA DE PARTIDOS Y LA RECONFIGURACIÓN DE LAS ELECCIONES?}

La crisis grave de 2009 constituyó la puerta de entrada de una transición política que tuvo una etapa clave en la elección de 2013. Ésta mostró los rasgos del sistema partidario, político y electoral que tuvieron una fisura o desaparecieron, sin que los alcances de la

\footnotetext{
${ }^{97}$ Torres, Manuel, Honduras: la transición inconclusa hacia una democracia, Tegucigalpa, Caritas-Subirana, 2012, pp. 86-96.

${ }^{98}$ Mejía, Thelma, "Political Reform and Civil Society's Participation", en Hemisphere Initiatives, Deciphering Honduras, Cambridge-Massachusetts, Hemisphere Initiatives, 2002, p. 24.

${ }^{99}$ Martínez, Juan Ramón, “El capitalismo de compadres”, La Tribuna, 23 de mayo de 2014.

${ }^{100}$ Programa de las Naciones Unidas para el Desarrollo, Informe sobre desarrollo humano Honduras 2011, Tegucigalpa, PNUD, 2012, p. 48.
} 
Este obra forma parte del acervo de la Biblioteca Jurídica Virtual del Instituto de Investigaciones Jurídicas de la UNAM

reconfiguración se encuentren ya establecidos. La transición histórica replantea la configuración bipartidista, el lugar de las elecciones y el signo de la participación.

El centenario bipartidismo ha desaparecido, sin implicar que el PN y el PL dejen de ser relevantes: permanecen en la primera línea sólo que ya no son los únicos en el escenario. Resquebrajamiento tanto más probable que no lo protegía un mecanismo de corte mayoritario, sólo el hábito de los electores. Su permanencia con un sistema proporcional constituía, más bien, una singularidad en América Latina. Las reglas facilitaron que la llegada de nuevos partidos, con convocatoria electoral, trastocara el bipartidismo en un multipartidismo en apenas una elección.

El impacto mayor de la crisis de 2009 para el sistema partidario fue el quiebre del PL. Una fracción permaneció alrededor de la sigla histórica, súbitamente desplazada hacia posiciones conservadoras, porque la caída de Zelaya fue orquestada por dirigentes liberales, destiñendo las credenciales antigolpistas del partido (Zelaya fue reemplazado por su correligionario Roberto Micheletti, hasta ese momento presidente del Congreso) y sobre todo por la escisión de las alas progresistas que terminaron de desvincular al PL de un proyecto de cambio sociopolítico. La otra fracción compuesta por dirigentes, cuadros y militantes seguidores del expresidente Zelaya, aliados con sectores de izquierda hasta entonces dispersos o activos en círculos sociales más que políticos fundó el partido Libre. En otros términos, uno de los dos partidos tradicionales se dividió y no se trata de una ruptura minoritaria. De hecho, Libre superó al PL en la presidencial de 2013.

La primaria de 2012, disputada por tres partidos, perfiló el nuevo escenario. Los nacionalistas emergieron vencedores conservando aproximadamente la mitad del cuerpo electoral (46.5\%), en las elecciones internas más reñidas de la historia: el vencedor Hernández quedó por debajo del 50\% y el asegurar la cohesión le representó un desafío. El PL llegó al segundo rango (29.2\%), con una estrecha victoria de Mauricio Villeda, hijo del más importante presidente liberal del siglo XX. El partido Libre reunió 24.1\%, su candidata Xiomara Castro, esposa de Zelaya, resultó individualmente la candidata más votada, aprovechando la candidatura de consenso presentada por el partido. La primaria confirmó la debilidad electoral de la izquierda, cuyo movimiento interno para la parlamentaria en Libre quedó relegado frente a las corrientes de ex liberales, más experimentados en los usos y costumbres electorales. Desde el inicio, Libre mostró sus raíces liberales, con votaciones significativas en la mayoría de los departamentos, gracias a estructuras que no necesitó crear sino apenas activar a partir 
Este obra forma parte del acervo de la Biblioteca Jurídica Virtual del Instituto de Investigaciones Jurídicas de la UNAM

de antiguas redes partidarias, y se superpuso a una geografía colorada. Sus bastiones se afincaron en el norte, con una presencia más rural que urbana, y sus debilidades se manifestaron en las áreas tradicionalmente nacionalistas.

El nacimiento de Libre impactó en el sistema partidario. La división del PL sería clave por sí misma. Como ocurrió cada vez que uno de los dos partidos mayoritarios sufrió una escisión significativa, perdió frente al partido que conservó la cohesión. En 1923 Carías triunfó contra dos candidatos liberales; en 1954 Villeda ante dos nacionalistas. Adicionalmente, por más que sus dirigentes centrales provengan del liberalismo y sus prácticas prolonguen los estilos precedentes, Libre introdujo un componente ideológico poco habitual. Trajo una plataforma de reformas políticas, sociales, económicas, cristalizadas alrededor de la Asamblea Constituyente, ${ }^{101}$ que en el principio del siglo XXI latinoamericano, por la experiencia andina, implica la apuesta por una reformulación de las bases del poder alrededor de un liderazgo fuerte con una amplia movilización social. ${ }^{102}$ Por eso, el planteamiento de Libre se afiliaba poco a la tradición de constituyentes hondureñas de la segunda mitad del siglo XX y desafiaba los límites en los cuales se movían liberales y nacionalistas. No obstante, en la campaña hizo escaso énfasis en asuntos ideológicos y exhibió su dependencia del liderazgo de Zelaya, jefe del partido. Junto con el PAC de Salvador Nasralla, Libre es el partido que tiene el cariz más personalista. La candidatura de su esposa constituyó la versión local de la "reeleccionismo conyugal", tendencia visible en América Latina a principios del siglo XXI. ${ }^{103}$

De manera paralela, el sistema de partidos que funcionó con dos grandes partidos y tres pequeños desde los años noventa, se transformó cuando el TSE reconoció cuatro nuevas organizaciones (2012). Al citado Libre se añadieron Alianza Patriótica, con una visible presencia de exmilitares, encabezado por Romeo Vásquez, comandante de las Fuerzas Armadas en los eventos de 2009, y el Frente Amplio Popular en Resistencia

\footnotetext{
${ }^{101}$ Libre, Planteamiento político de las bases del plan de gobierno para una Honduras libre, Tegucigalpa, Libre, 2013, pp. 13-17.

${ }^{102}$ Cfr. Romero Ballivián, Salvador, “Procesos constituyentes andinos: de Colombia a Bolivia 1990-2009”, Diálogo Político, 2010, pp. 85-108.

${ }^{103}$ Zovatto, Daniel, El estado de las democracias en América Latina, Lima, Jurado Nacional de Elecciones, 2014, p. 45.
} 
Este obra forma parte del acervo de la Biblioteca Jurídica Virtual del Instituto de Investigaciones Jurídicas de la UNAM

(FAPER) del activista de los derechos humanos, Andrés Pavón. Estos partidos confirmaron la importancia de 2009 en la reconfiguración del juego político y la persistencia de la polarización que estalló ese año pero, al final, sus resultados electorales fueron mínimos. Por último, el popular comentarista deportivo Nasralla creó el PAC, con un perfil de "outsider" cabalgó sobre la denuncia de la corrupción y la descalificación del sistema político tradicional en una época de hartazgo con el estado político, económico, social y de seguridad del país. Prometió renovar la política y colocó en las planillas parlamentarias y municipales a personas sin vínculos partidarios.

En este ambiente, llegó la elección general de 2013 conducida por el gobierno de Porfirio Lobo, ganador de la presidencial de 2009, celebrada con el visto bueno implícito más que el apoyo internacional explícito, en la medida que se la entendía como el camino más expedito para reencauzar la legitimidad política. ${ }^{104}$ Lobo logró en el Acuerdo de Cartagena (2011) las condiciones para el retorno político y jurídico de Zelaya a Honduras, un paso previo decisivo para la vuelta plena de Honduras a la comunidad internacional, simbolizada por la readmisión del país en la Organización de Estados Americanos (OEA). En otros campos, el balance resultó menos halagador y al final de la gestión, la ciudadanía identificaba como prioritarios los mismos desafíos que al inicio. La seguridad continuó degradándose, alimentada por la presencia del narcotráfico en la costa norte, las maras y pandillas en las ciudades grandes y una delincuencia ordinaria, particularmente violenta. El crecimiento económico resultó corto, y lenta la recuperación de la crisis que en 2008 sufrió los Estados Unidos, socio fundamental para Honduras. La anemia económica impidió mejoras significativas en el empleo, los ingresos y en la reducción de la marcada desigualdad, en tanto que se agudizó el déficit fiscal. Por último, los ciudadanos percibieron como alarmante la corrupción en el Estado.

La campaña de 2013 se realizó con esas inquietudes como telón de fondo. Si bien, la campaña se desarrolló en un ambiente de relativa calma entre los partidos, entre enero y diciembre de 2013 se registró el asesinato de seis candidatos: tres para el cargo de alcalde, dos para el de regidor, uno para diputado, además de un alcalde, dos vicealcaldes $\mathrm{y}$ dos regidores en ejercicio y al menos seis familiares cercanos de candidatos (ellos se sumaron a los siete candidatos para alcalde y tres candidatos a

\footnotetext{
${ }^{104}$ Instituto Nacional Demócrata, Informe final misión internacional de estudio y acompañamiento elecciones generales de Honduras 2009, Washington, Instituto Nacional Demócrata, 2010 p. 1.
} 
Este obra forma parte del acervo de la Biblioteca Jurídica Virtual del Instituto de Investigaciones Jurídicas de la UNAM

diputado asesinados en las primarias de 2012). ${ }^{105}$ El móvil político no pudo ser siempre establecido. El aletargamiento de la economía no impidió el mayor flujo de recursos a las campañas proselitistas de la historia, acentuando la tendencia previa. El PN fue el más beneficiado y por rubros, el pedazo grande de la torta de gastos se destinó a la televisión, ${ }^{106}$ como en la mayoría de las democracias latinoamericanas. La rendición de cuentas sobre el origen, el monto, el destino de los recursos recibidos por los candidatos, el monitoreo de los gastos y la imposición de sanciones por infracciones permanecen entre los desafíos de la ley electoral.

La campaña presagió el final del bipartidismo por la renovada y ampliada oferta política. Los nuevos partidos, en especial Libre y PAC, compitieron contra los dos históricos. El cambio y el statu quo polarizaron la campaña, contrapusieron dos candidatos y dos agendas. Libre insistió en refundar las bases del Estado y la sociedad en una Asamblea Constituyente. Sin desmarcarse del gobierno, Hernández — del PNofreció ampliar el "Bono 10.000" para familias de mínimos ingresos y para entrar en sintonía con la prioritaria demanda de seguridad propuso aumentar la presencia de la recién conformada policía militar en las calles, contraponiéndola a la voluntad de Libre, de replegar a los militares. Simultáneamente procuró asociar la candidatura de Castro con el chavismo para generar temor. A un mes de los comicios empató a Castro en las intenciones de voto después de ir atrás durante la mayor parte del año. ${ }^{107}$ En el escenario polarizado, Villeda y Nasralla tuvieron complicaciones para descollar. Al final, Villeda que se colocó como abanderado de la honestidad y cuestionó tanto la administración nacionalista como los principios de Libre a un mes de los comicios, apeló al sentimiento liberal para recuperar el voto histórico del partido.

La polarización arrastrada desde 2009, la diversificación de la oferta y un resultado apretado que se anticipaba beneficiaron la participación electoral que remontó hasta $61.1 \%$, los sufragios blancos y nulos se mantuvieron bajos $(4.8 \%$ del total de votos emitidos).

Las características novedosas del proceso se reflejaron geográficamente: por primera

\footnotetext{
${ }^{105}$ Instituto Universitario en Democracia, Paz y Seguridad Jurídica, Informe final de la conflictividad y violencia política electoral, Tegucigalpa, Instituto Universitario en Democracia, Paz y Seguridad Jurídica, 2014.

${ }^{107}$ Borge, Encuesta de opinión pública 85, octubre de 2013 (inédita).
} 
Este obra forma parte del acervo de la Biblioteca Jurídica Virtual del Instituto de Investigaciones Jurídicas de la UNAM www.juridicas.unam.mx

vez cuatro partidos distintos se impusieron en al menos un departamento (mapa 1).

\section{Mapa 1}

\section{Presidencial de 2013: ganador por departamento}

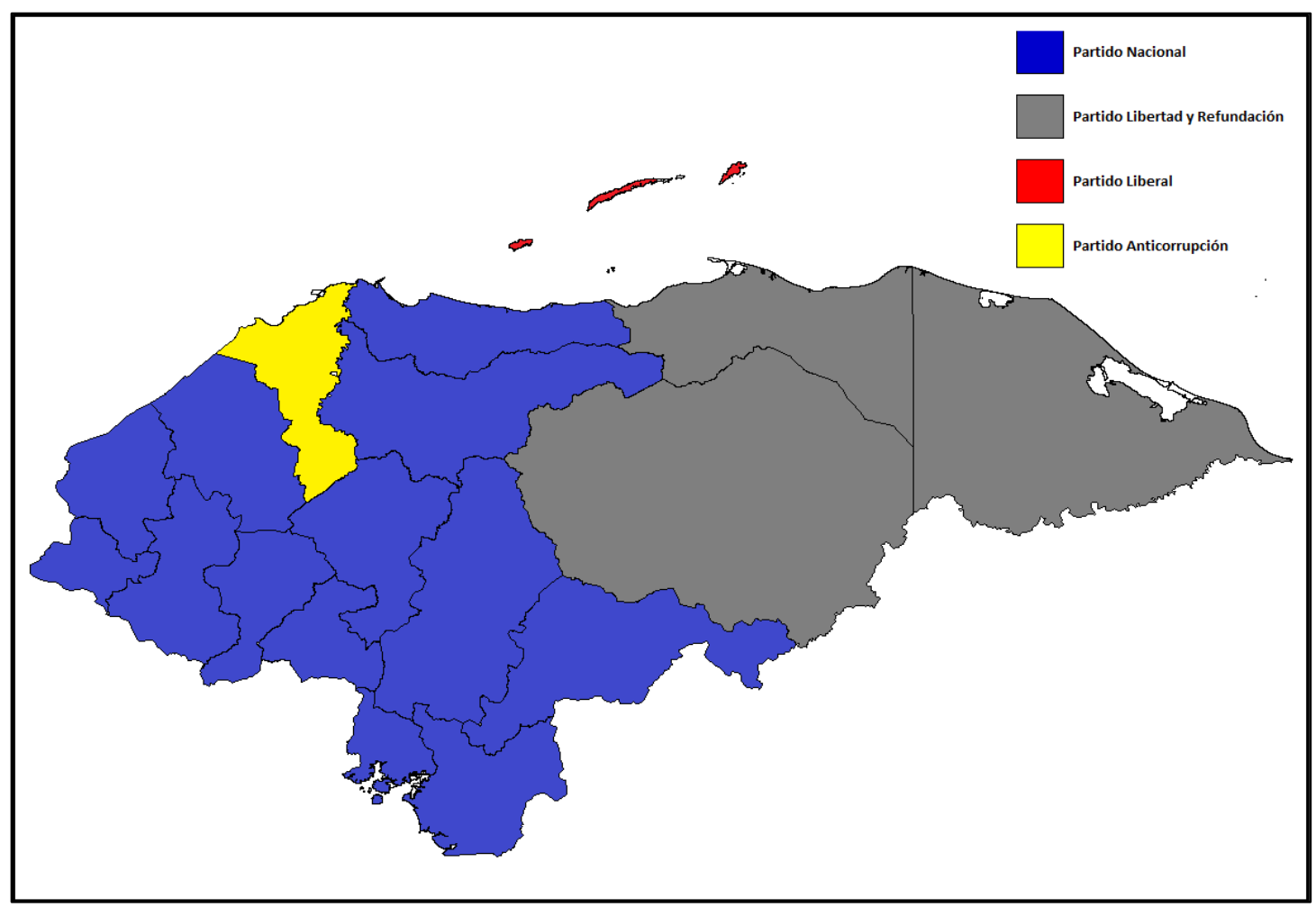

La elección probó el éxito de la estrategia de Hernández del PN, ganador con 36.8\% de votos válidos. Se impuso en la mayoría de los departamentos, afianzándose sobre todo en el occidente y sur, rural, de menor desarrollo humano y acostumbrada fortaleza partidaria. En el quiebre del bipartidismo, el nacionalismo aprovechó su unidad frente a la división de su adversario y pese al desgaste de la gestión, traducida en la pérdida de una veintena de puntos, conservó la presidencia. Con respecto a 2009, retrocedió en todos los departamentos, con caídas limitadas en su bastión y descensos marcados en las áreas urbanas. La ruralización partidaria se acentuó. La votación por Hernández creció entre la población de más edad, apegada al sistema partidario tradicional, femenina, de menor escolaridad e ingreso, ${ }^{108}$ sectores que buscaron preservar el "bono 10.000 ". Su énfasis en la seguridad con una oferta percibida como concreta y clara, fue igualmente clave.

\footnotetext{
${ }^{108}$ Los datos sobre el perfil del electorado provienen de Borge y Asociados, Encuesta nacional de opinión pública postelectoral 2013, op. cit.
} 
Este obra forma parte del acervo de la Biblioteca Jurídica Virtual del Instituto de Investigaciones Jurídicas de la UNAM

El segundo lugar lo ocupó Castro, de Libre con $28.7 \%$, quien canalizó una parte de la ambición de cambio latente pero no logró despejar completamente el temor de las acciones que podría adoptar, a pesar del tono moderado de la campaña. En el reparto de tierras dejado por la división liberal se apropió del noroeste rural, de escaso desarrollo, juntó el periférico Gracias a Dios, Olancho, departamento de Zelaya, y Colón, área de movimientos campesinos enfrentados a empresarios de la tierra en las proximidades del Bajo Aguán. Ciudades y áreas rurales se equilibraron. El votante de Libre tuvo un perfil masculino, juvenil y a la vez mayor de 50 años, con buen nivel educativo.

Villeda del PL reunió $20.2 \%$ y se colocó en tercer lugar. El partido perdió 17.9 puntos y su caudal casi se dividió por la mitad con relación a la presidencial anterior, que ya había sido el peor desempeño de la organización. La geografía clásica se desdibujó por el debilitamiento en el norte, con la excepción de las Islas de la Bahía, y la mejor resistencia en el sur. Se trató de una geografía novedosa, sureña, urbana y próspera. Sin embargo, el perfil del electorado retrató una persona de edad avanzada, poco escolarizada, con una crisis de lealtad partidaria: Villeda fue el candidato que menos movilizó entre los simpatizantes de su propia organización, víctima de la polarización entre el PN y Libre. Ese mismo día, los alcaldes liberales reunieron un caudal de votos mayor que el candidato presidencial y, de hecho, el PL ocupó la segunda plaza en las municipales, por la cantidad de alcaldes y regidores.

EI PAC de Nasralla quedó en la cuarta casilla con $13.5 \%$, con un sonado triunfo en el departamento de Cortés, corazón industrial y urbano, con el área metropolitana San Pedro Sula-Choloma-La Lima-Puerto Cortés. Se superpuso a la Honduras urbana y de mayor desarrollo humano. La votación confirmó la importancia en la sociedad contemporánea de la televisión para proyectar liderazgos sin un aparato partidario vigoroso: ${ }^{109}$ esa influencia se sintió en las ciudades, en cambio, cubrir las zonas rurales menos influidas por los medios de comunicación de masas y las redes sociales virtuales, exigía una estructura que no tenía el PAC. En seis departamentos quedó por debajo del $4 \%$. Sumó un destacado apoyo juvenil, de sectores escolarizados, de grupos que tendían a permanecer al margen de los procesos políticos y expresaban desde antes la predisposición a votar por un "partido nuevo". ${ }^{110}$ Encontraron en PAC la oportunidad

\footnotetext{
${ }^{109}$ Cfr. Sartori, Giovanni, Homo videns, Buenos Aires, Taurus, 1999, pp. 105-116.

${ }^{110}$ Instituto Nacional Demócrata, op. cit., p. 53.
} 
Este obra forma parte del acervo de la Biblioteca Jurídica Virtual del Instituto de Investigaciones Jurídicas de la UNAM

para manifestar su descontento y exigir un nuevo estilo de hacer política. Por detrás, cuatro candidatos no superaron juntos la barrera del 1\%, incluidos los tres partidos hasta entonces denominados "emergentes" (PDC, PINU, UD, en contraposición a los "históricos") que parecieron amoldados al sistema tradicional.

La elección dejó, al menos, cuatro grandes resultados y lecciones políticas; marcó el final del bipartidismo. El PL relegado al tercer lugar, y el PN sumaron menos de 60\%, lejos del 95\% de costumbre. Ambos perdieron casi la misma cantidad de puntos, alrededor de una veintena. Fue, además, de manera individual su peor desempeño ante la democracia. Consecuencia de la ruptura del bipartidismo, la alternancia entre nacionalistas y liberales ya no constituye el horizonte único. En el esquema previo, elección más, elección menos, uno de los dos grandes partidos sabía que accedería a la presidencia y el otro que la perdería para iniciar un ciclo inverso. Con la diversificación de actores, esa seguridad pierde fundamento. El impacto de esta incertidumbre pesa más sobre el liberalismo y junto con la arraigada tradición bipartidista explica un incipiente movimiento desde las bases del PL y de Libre para avanzar hacia una alianza o reunificación, como ilustró un pedido de alcaldes y diputados de Comayagua de ambos partidos en 2014. ${ }^{111}$ La multiplicación de partidos puede también impactar en la cohesión de éstos, antes preservada por el bipartidismo. Ahora, dirigentes medios o altos pueden dejar sus organizaciones sin cruzar la línea hacia el adversario histórico y hallar oportunidades en las formaciones recientes, cuyas estructuras se encuentran en formación. La onda de repercusiones del quiebre del bipartidismo está lejos de haberse agotado. La transformación es evidente en el plano nacional; en el nivel municipal, el bipartidismo resistió mejor reteniendo casi $90 \%$ de las alcaldías. El PN y el PL se apoyaron en el trípode del poder local: rostros conocidos en busca de la reelección, estructura partidaria funcional y redes sociales bien constituidas.

La segunda lección es que la rutina de elecciones periódicas no disipa la recurrente desconfianza en la transparencia de los comicios ni de cuestionamiento a los resultados, pese a los informes positivos de las misiones de observación electoral de la UE, la OEA y el consorcio "Hagamos Democracia" (conformado por Caritas, la Confraternidad Evangélica, FOPRIDEH y la Universidad Metropolitana). Castro y Nasralla dudaron del escrutinio oficial, apelaron a la vía jurisdiccional y sobre todo a la denuncia pública y la

\footnotetext{
111 “Alcaldes de Comayagua piden alianza PL-LIBRE”, La Prensa, 2 de agosto de 2014.
} 
Este obra forma parte del acervo de la Biblioteca Jurídica Virtual del Instituto de Investigaciones Jurídicas de la UNAM

presencia mediática desde el mismo día de la elección. Es común que en la noche de los comicios, más de un candidato se proclame ganador y que luego el vencido tarde semanas en conceder la derrota, si alguna vez lo hace de forma explícita. Así, 44.7\% de los encuestados señalaron tener poca o ninguna confianza en que los resultados reflejaron las preferencias ciudadanas, grupo en el cual sobresalen simpatizantes de Libre, PAC y personas sin identificación partidaria.

En tercer lugar, Hernández comenzó su gestión con el Congreso más fragmentado de la historia hondureña. Su bancada tiene algo más de un tercio de los escaños. Se puede anticipar que los gobiernos monocolores se harán excepcionales: con un parlamento en el que el partido del presidente dista de la mayoría absoluta para aprobar leyes, la necesidad de formar coaliciones de gobierno entrará en la agenda política, como sucede de manera ordinaria en los regímenes multipartidistas de representación proporcional. EI PN requiere pactos estables o ad hoc, para aprobar leyes. Para el inicio de la legislatura contó con un acuerdo implícito de gobernabilidad con el PL, reforzando la percepción de un escenario en el cual los actores del bipartidismo forman un polo frente a los nuevos partidos. Además, el gobierno encara una situación fiscal precaria, una inseguridad estabilizada en niveles muy elevados, un sistema partidario y político en renovación, en una muda que ha tenido en los comicios de 2013, uno de sus hitos más importantes pero no el único ni el último. La presidencial de 2013 fue sólo la elección de la transición hacia un sistema electoral, partidario y político que continuará rediseñándose en los próximos años.

Por último, si la reconfiguración del centenario sistema de partidos parece segura, la evolución de las elecciones y sobre todo de la participación es menos sencilla de predecir. Es previsible que la calidad técnica y las garantías de transparencia e imparcialidad para los distintos actores de los procesos electorales continúen en alza. El organismo electoral registra mejoras administrativas, técnicas y logísticas en la administración de los procesos, fruto de la combinación del aprendizaje de lecciones, así como la progresiva profesionalización de su personal y la asistencia externa brindada por PNUD, OEA o IFES.

Como en otros países, los controles internos y externos se vuelven más sistemáticos y efectivos, con la llegada de misiones de observación internacional y el despliegue de la observación local. La sociedad se muestra menos dispuesta a aceptar prácticas a las cuales se responsabiliza de enturbiar la jornada electoral: distribución en blanco de credenciales de miembros de mesa, que se presta a un comercio de dichas tarjetas en 
Este obra forma parte del acervo de la Biblioteca Jurídica Virtual del Instituto de Investigaciones Jurídicas de la UNAM

beneficio de las grandes corrientes o de los partidos mayores, que por lo tanto ganan un peso adicional en la mesa; ${ }^{112}$ composición exclusivamente partidaria de la mesa receptora de votos, que permitiría manipulaciones de las actas que el TSE sólo tabula; ausencia de controles básicos y de sanciones en el financiamiento de la campaña que facilita el clientelismo, campañas muy desiguales y costosas.

Esos puntos flacos, aunque conocidos, estallaron en las primarias de 2012 probablemente por las singularidades de esa elección, a la cual acudían tres partidos en un ambiente polarizado, y saldada con los resultados más estrechos de la historia de las primarias. La presidencial de 2013 arrastró esas dificultades. Muchas de las demandas encontraron eco en un proyecto de una reforma sustantiva de la legislación electoral presentada por el TSE, que proponía el financiamiento permanente a los partidos, controles reforzados sobre los gastos partidarios, el fortalecimiento de las competencias del organismo electoral, pasos para una presencia apartidista en las mesas de votación. ${ }^{113}$ Los planteamientos se encuentran alineados con las tendencias dominantes de la reforma política en América Latina. ${ }^{114}$ Sin embargo, las fuerzas políticas todavía manifiestan reservas ante la perspectiva de cambios significativos que recorten sus facultades de intervención y control sobre el proceso electoral.

El futuro de la participación electoral se mantiene bajo un signo de interrogación. En efecto, Honduras ha ingresado a una fase en la cual las alarmas se disparan por la subida del escepticismo y el desapego ciudadano hacia los actores, las instituciones, las prácticas de la democracia tal y como funciona. Los números están en su punto más bajo, ya sea en la comparación interna, con las mediciones anteriores en Honduras, y externa, en relación a los otros países latinoamericanos. Para 2012, el apoyo al sistema y a la democracia cayeron al punto más bajo en América Latina desde que se realiza la

\footnotetext{
${ }^{112}$ El Tribunal Supremo Electoral admite la existencia del problema y la dificultad de enfrentarlo por la ausencia de denuncias formales. "Venta de credenciales se va a terminar hasta que "enchanchemos un par", El Heraldo, 14 de noviembre de 2012 (declaración del magistrado Enrique Ortez).

${ }^{113}$ Tribunal Supremo Electoral, Proyecto de ley para la participación política y electoral, Tegucigalpa, Tribunal Supremo Electoral, 2011.

${ }^{114}$ Romero Ballivián, Salvador, “La búsqueda de la equidad: breve guía sobre las reformas políticas y electorales latinoamericanas a principios del siglo XXI", en Cuadernos de CAPEL (57), 2012, pp. 289-310.
} 
Este obra forma parte del acervo de la Biblioteca Jurídica Virtual del Instituto de Investigaciones Jurídicas de la UNAM www.juridicas.unam.mx

encuesta del Barómetro de las Américas en 2004. ${ }^{115}$

En ese escenario, la presencia de nuevos partidos y candidatos revitalizó la participación electoral. Las primarias de 2012 y las generales de 2013 ofrecen una indicación en ese sentido, ya que la diversificación de la oferta y la pugnacidad de la contienda incrementaron la participación en casi una decena de puntos con respecto a la primaria y la presidencial previas. Sin embargo, sólo futuros comicios mostrarán si se confirma la remontada, si ella fue apenas un sobresalto en una línea descendente o si marca un periodo de estabilización. Es probable que cualquiera de esas evoluciones se produzca en un contexto de democracia de baja calidad, recurrentes crisis institucionales y una mezcla de apatía, y descontento crecientes. Las elecciones en Honduras se encuentran bajo la alerta de huracanes.

\footnotetext{
${ }^{115}$ Vanderbilt University, Cultura política de la democracia en Honduras y en las Américas 2012, Tegucigalpa, Vanderbilt University, 2012, pp. 119-140.
} 